\title{
Economic Interventions, Economic Perceptions and Political Support During the Eurozone Crisis
}

\author{
Daniel Devine* $\quad$ Stuart J. Turnbull-Dugarte ${ }^{\dagger}$ \\ Conditionally accepted for publication in \\ Political Science Research \& method
}

\begin{abstract}
What is the effect of external economic intervention on political support and economic evaluations? We argue that economic interventions systematically worsen support for governing institutions and much of this is mediated through updating economic perceptions, at least during the Eurozone crisis. We evidence this with two analyses. First, we provide the first quasi-experimental evidence to show that intervention worsened both political support and economic evaluations. Second, we conduct a mediation analysis using longitudinal Eurobarometer data to quantify how much of the effect of intervention is mediated by economic evaluations. This has broader implications for understanding how citizens react to international integration, international cues, and the process of forming judgements of political support.
\end{abstract}

*St Hilda's College, University of Oxford. daniel.devine@st-hildas.ox.ac.uk

${ }^{\dagger}$ Department of Politics \& IR, University of Southampton. s.turnbull-dugarte@soton.ac.uk 


\section{Introduction}

During the height of the Eurozone crisis, European citizens, particularly those in the bailed-out debtor countries, lost support for their political institutions, identified as satisfaction with democracy and trust in political institutions. What's behind this collapse in political support is a fundamental debate in the political support literature: to what extent was it a function of the dire economic situation (Devine, 2019; Foster \& Frieden, 2017), or a more intrinsic loss of faith about the workings of the domestic, democratic system of governance (Armingeon \& Guthmann, 2014; Armingeon et al., 2016; Sánchez-Cuenca, 2017)? This question speaks to the concern that national-level democracy is being hollowed out by the influence of actors beyond the domestic sphere, resulting in greater detachment from domestic, governing institutions (Laffan, 2014; Mair, 2013; Scharpf, 1999; Vowles \& Xezonakis, 2016). This was seen to be exemplified by the Eurozone crisis, where the economic interventions by the European Commission, International Monetary Fund (IMF) and European Central Bank (ECB), known collectively as the Troika, imposed a set of structural reform programmes upon a number of European Union (EU) countries. This led to claims that democratic governance in Europe had been relegated to being a system of 'democracy without choice', a 'democratic void', or suffering from 'democratic impotence' (Alonso, 2014; Sánchez-Cuenca, 2017).

Whilst recent empirical contributions conclude that interventions resulted in a decline of political support, understood as both trust in political institutions and satisfaction with democracy, over and above the existing economic distress (Armingeon \& Guthmann, 2014; Schraff \& Schimmelfennig, 2019), there are crucial missing gaps within this literature. First, the majority of analyses (though see Armingeon \& Guthmann, 2014) are conducted at the aggregate level, leaving 'uncharted territory' at the individual level (Schraff \& Schimmelfennig, 2019). The result is that whilst we have firmly established that interventions affect political support, we do not know whether this is a causal relationship, if it operates at the individual level, or through which mechanisms. Second and related, we do not have a convincing answer to whether the mechanism is one of economic 
distress, concerns over democratic legitimacy, or something else entirely. These questions address issues of democratic governance under interdependence and how people process such information.

In this paper, we address both of these gaps by triangulating analyses at the aggregate and individual-level to provide an empirical contribution to our understanding of the intervention-induced collapse in political support. First, we contribute novel individuallevel causal evidence of the negative impact of economic interventions on political support and economic perceptions from a quasi-experiment in Portugal, in which a press release announcing an intervention (and the conditional reform measures required of the Portuguese state) occurred during survey fieldwork. Second, we consider the hypothesis that the link between interventions and political support is through subjective economic evaluations, what we call the economic cue thesis: news of intervention acts as an information shock, which catalyses a learning process that updates individuals' understanding of how the economy is performing and, more importantly, how the economy is likely to perform in the near future. We study this with a mediation analysis through a structural equation model on aggregate Eurobarometer data from all EU countries between 2005 and 2015 (293 country-years), which decomposes the overall effect of intervention into its direct and indirect components. This allows us to quantify both whether intervention influenced economic perceptions or political support and how much of the effect of interventions on the latter operates through economic evaluations. Due to there being no survey questions for the 'reduced manoeuvrability' mechanism, we can only test this through 'objective' measures such as national interest rates, and so our evidence on this mechanism is indirect.

The results of these two complementary studies show that interventions exhibited a negative causal impact on both political support and economic perceptions. The mediation analysis shows that the negative effect of intervention from the EU is partially mediated by updates in economic priors, supporting the economic cue thesis. Yet, approximately two thirds of the effect of the intervention is through other mechanism(s). As such, whilst 
we are confident that the economic route explains a sizeable proportion of the collapse in political support, we attribute the rest to a combination of the 'democratic impotence' mechanism, some unidentified causal path, as well as random error. Whilst the theoretical models point towards democratic impotence, the data available does not permit us to isolate this path. Still, our analysis allows us to provide a unique assessment of the extent to which interventions affected political support and how much is via the rational updating of economic priors. Finally, we show that objective economic conditions (such as unemployment change, GDP, and overall economic 'misery' (Kriesi, 2016)) only affect political support via their influence on economic perceptions. Overall, we provide robust and rigorous causal evidence for the effect of economic interventions on political support and quantify the extent and pathways through which they operate.

In the next section, we present the existing literature and our hypotheses. We then describe our data and methods and present our results, and conclude with a brief discussion.

\section{EU intervention and political support}

The intervention of the EU into the domestic economies of its member states began at the height of the Eurozone crisis in 2010 when, faced with insurmountable borrowing costs, the Greek government became the first country to sign a financial bailout package with the Troika. Memorandums of Understanding instigating processes of intervention and fiscal monitoring between the Troika were later signed by Ireland (2010), Portugal (2011), Spain (2012) and Cyprus (2013). Italy, although not a formal signatory of an agreement with the Troika, was also informally subjected to intervention by the ECB - as was Spain - in 2011. The then president of the ECB (Jean-Claude Trichet) clandestinely wrote to each country's head of government requiring a battery of fiscal reforms and internal devaluation measures to be implemented in order for the countries to qualify for future financial assistance. ${ }^{1}$ Submitting their citizens to the conditions demanded by

\footnotetext{
${ }^{1}$ This unprecedented step by the ECB was of questionable legitimacy as it went far beyond the provisions of the Treaty that stipulates its mandate (Heldt \& Mueller, 2020; Schmidt, 2015)
} 
European creditors, the governments of the intervened-in member states are viewed as having abdicated their duty to act responsively to the policy preferences of their voters via the prioritisation of economic responsibility to their member state peers (Alonso, 2014; Laffan, 2014; Turnbull-Dugarte, 2020b).

The EU's decisions to intervene in member state economies has had a profound effect on party politics, electoral behaviour and public opinion, shaping our broad understanding of the workings of electoral democracy. It is argued to have shaped the 'quality' and legitimacy of democracy in Europe (Morlino \& Quaranta, 2016; Sánchez-Cuenca, 2017). Issue salience, particularly on the dimension of EU integration (Katsanidou \& Otjes, 2015; Otjes \& Katsanidou, 2017; Turnbull-Dugarte, 2020a), has been changed, party systems reconfigured and responsiveness reduced (Traber et al., 2018).

Arguably the most significant effect, and certainly of most relevance to our argument, is that intervention transformed citizens' attachments to their political system - such as satisfaction with democracy and trust in institutions, which we refer to as political support. Using a range of methods, data sources and indicators, the literature has established that the Eurozone crisis shattered political support, particularly in Southern Europe, and through multiple mechanisms. Armingeon et al. (2016) have highlighted, for instance, how citizens in debtor countries have become detached from their political systems, ultimately severing the ties of legitimacy between the governed and governors; in doing so, dividing the Union between debtor and creditor countries. Armingeon and Guthmann (2014) also report a notable collapse in both the level of satisfaction with democracy (SWD) and trust in the national parliament amongst the bailout recipient states. RuizRufino and Alonso (2017) find similar evidence from a difference-in-difference estimation, which shows that the intervened-in countries experienced much lower levels of democratic satisfaction than creditor countries, which even increased in satisfaction (such as Germany). Schraff and Schimmelfennig (2019) provide evidence of the same negative effect, with variation in intensity depending on country, using a generalised synthetic control model; a negative effect which, however, fades over time as economic conditions 
improve. Whilst the vast majority of work finds a negative intervention effect, this conclusion is not uncontested, with some finding that there was a muted effect on support (Magalhães, 2016), and intervention in fact bolstered support for democracy as a regime principle (Cordero \& Simón, 2016). With respect to the interventions, then, the literature generates a clear hypothesis:

H1: EU economic intervention reduces satisfaction with democracy and political trust at the national level.

\subsection{EU interventions, economic evaluations and citizen updat- ing}

The main question that remains in the literature is what links external economic interventions with political support. This is an important omission as it tells us about the nature of political support and the role of governing institutions (domestic or otherwise) in fostering or eroding it. Devine (2019) outlines three pathways. Two fall under the reduced manoeuvrability thesis ${ }^{2}$, which posits that intervention by a supranational or international institution ties the hands of domestic governments limiting their ability to offer distinct policy alternatives to their voters that diverge from the conditions demanded of them by their external creditors (Alonso, 2014). This reduced manoeuvrability leads to a situation in which voters are no longer able to choose the policy direction of the state resulting in a 'democracy without choice'. It is this lack of choice that distinguishes the manoeuvrability-constraining nature of EU intervention, and the welfare state retrenchment packages required by the intervening institutions, from bread and butter austerity politics.

Throughout the years that followed the financial crisis a number of states in Europe, both within and outside of the Eurozone, adopted austerity as a standard policy response (Blyth, 2013). Austerity, and the democratic discontent that it led to (Huebscher et al.,

\footnotetext{
${ }^{2}$ Schraff and Schimmelfennig (2019) refer to this as the 'democratic detachment' thesis
} 
2020), was not an implemented public policy unique to the the intervened-in countries. What was unique to the intervened-in states, however, was the democratic legitimacy of reforms. Whilst British, German and Dutch citizens, to give illustrative examples, were subjected to austerity measures that were self-imposed by their governments, the citizens of the intervened-in states were subjected to these policies primarily because of external pressure (Javier, 2014; Ruiz-Rufino \& Alonso, 2017). A lack of choice undermines citizens' faith in representative democratic institutions which leads to a reduction in levels of political support and satisfaction with democracy (Ruiz-Rufino \& Alonso, 2017), political trust (Torcal, 2014), and a reduction in participation with the political and electoral process (Turnbull-Dugarte, 2020b). This can be either through citizens directly perceiving this constraint on maneuverability or only the lack of responsiveness of parties ${ }^{3}$ and the political class.

On the other hand, there is the subjective economic cue thesis (Devine, 2019; Foster \& Frieden, 2017). This theory maintains that economic intervention by external actors provides a cue to citizens that engenders information acquisition and learning regarding both the state of the economy as well as the competence of those in power to effectively manage the country's economic problems. When individuals observe their country in need of emergency financial support from supranational actors, they are cued to update and revise their (negative) economic evaluations and expectations. When economic times are hard, citizens tend to be less satisfied with democracy and less trusting, with the reverse being true when times are good (Christmann, 2018; Foster \& Frieden, 2017; Friedrichsen \& Zahn, 2014). Moreover, theories of economic voting assume that citizens' electoral and political choices are shaped by their evaluations of economic performance (Duch \& Stevenson, 2008) and the same has been observed in the case of political support, with negative economic conditions correlating with lower levels of trust and SWD (Christmann, 2018; Quaranta \& Martini, 2017).

\footnotetext{
${ }^{3}$ Alonso and Sánchez-Cuenca (2020), however, present causal evidence to show that citizens care little about the whether a lack of responsiveness is the product of domestic action or externally exposed constraints. Relying on a survey experiment in Spain, they show that a collapse in satisfaction with democracy can be attributed to austerity policies rather than the EU's solicitation.
} 
Whilst both of the theoretical mechanisms linking intervention and political support assume political learning, they diverge on the issue of what priors are being updated by the information shock. The reduced manoeuvrability thesis posits that it is the priors regarding the constraining nature of external actors which are updated, whilst the economic cue thesis argues that it is subjective economic evaluations which are updated. We test the hypothesis that economic interventions update economic evaluations in both quasi-experimental and observational settings. If we do not find that interventions update economic evaluations, this suggests either that citizens do not update their views or that the link between interventions and political support is not through economic evaluations:

\section{H2: EU economic intervention leads to worse economic evaluations}

We can also extend this logic further. Not only would we expect that interventions affect economic evaluations, we would also expect that at least some of the effect of interventions operates through their effect on evaluations; in other words, the effect is mediated. This is an important area of contention within the extant literature on the effects of external intervention. Whilst Ruiz-Rufino and Alonso (2017) posits that the negative correlation between intervention and political support is the product of citizens' realisation that external actors are constraining the responsiveness of domestic institutions to their preferences, Devine (2019) and Schraff and Schimmelfennig (2019) maintain that political support is determined by the negative economic expectations. We thus directly test whether the effect of the intervention on political support is mediated by economic evaluations. In doing so, we are able to isolate how much of the effect of the intervention is transmitted via economic perceptions. ${ }^{4}$

H3: Negative effect of EU intervention on political support is mediated by updates in economic evaluations (economic cue thesis)

\footnotetext{
${ }^{4}$ Unfortunately, we are unable to directly test competing hypotheses, such as the reduced manoeuvrability thesis, due to data limitations. Of note is that assessing this mechanism directly is an empirical challenge given the lack of cross-national and time-constant survey instruments that allow one to measure respondents' understanding of the level of government autonomy and constraints.
} 


\section{Data \& Methods}

Empirically, we employ a two-stage analytical approach using Eurobarometer data. Firstly, to test $\mathrm{H} 1$ and $\mathrm{H} 2$ we use an unexpected event design (Muñoz et al., 2020) to provide quasi-experimental evidence of the causal effect of intervention on both political support and economic evaluations at the individual level. A press release regarding an intervention was announced during Eurobarometer survey fieldwork in Portugal, providing us with an experimental setting where some respondents were interviewed before the press release and some were interviewed after. The data therefore provides the ideal setting to examine the effect of the as good as random exposure to the announcement regarding the EU's economic intervention on both economic perceptions and political trust at the individual level. Whilst the possibility of intervention existed before the confirmation announcement, the announcement still operated as an informational shock and we test extensively for pre-treatment trends in our dependent variables to show that the announcement led to a stark and significant discontinuity (Figures A2, A6, A7). We also reject related issues such as non-random sampling (Figure A4).

Our second stage of the analysis turns to the full Eurobarometer data in order to examine H3. The data comprises 293 country-year observations for all twenty-eight EU member states between 2005 and 2015. ${ }^{5}$ Using this aggregate-level data, we provide a mediation analysis using a generalised structural equation model which isolates the effect of EU intervention on SWD and the potential mediating role of economic perceptions. Specifically, we test whether EU intervention exhibits a direct effect on SWD, or if the relationship is mediated, with intervention serving as an information shock that leads to an updating of the public's assessment of the state of the economy. The following sections details the specific operationalisation and estimation techniques of each empirical test alongside the main results.

\footnotetext{
${ }^{5}$ Years prior to 2005 do not include indicators for economic perceptions. Bulgaria and Romania are included post-2007, Cyprus is included post-2008 and Croatia is included post-2013, after each country's respective accession to the EU.
} 


\section{Evidence}

\section{Study 1: Quasi-experimental analysis}

For the quasi-experimental study, we rely on the Eurobarometer (EB) 75.3 in May 2011, which occurred during the period in which Portugal requested and was granted a financial bailout package with strict conditionality from the EU institutions. Whilst Portugal requested a rescue loan on the 7th April and provided greater detail on the 5th of May, this was approved and given the go-ahead by the Eurogroup and ECOFIN ministers on the 16th of May. ${ }^{6}$ The announcement entailed greater monitoring of budget controls, reforms of the health, housing and services systems, and a catalogue of 'ambitious' privatisations. This was, of course, reported in the Portuguese press, which we provide examples of in the Appendix. Essentially, those with the potential to be exposed to the announcement were being informed of the Troika-solicited reforms and conditions attached to Portugal's bailout request.

The EB fieldwork in Portugal took place between 7th May and 22nd May, providing a sample both before and after the press release. As we do not have a measure of compliance (whether individual citizens actually became aware of the news), our core estimand is the intent-to-treat (ITT) effect. ${ }^{7}$ Given the exogenous nature of treatment allocation (exposure to the news regarding intervention and the conditions attached), we separate the sample into those interviewed before the press release (control) and those interviewed on or after the announcement was made (treatment). The control group comprises $77 \%$ of the sample $(N=803)$ whilst the remaining $23 \%(N=245)$ of respondents are assigned to treatment. We estimate the effect of exposure to the news regarding intervention whilst controlling for basic pre-treatment covariates: education, age, occupation and gender. ${ }^{8}$ Intervention is operationalised via a simple exposure binary indicator from the 17th of

\footnotetext{
${ }^{6}$ The statement can be accessed at ECOFIN (2011)

${ }^{7}$ We do not find asymmetric effects depending on political interest, the nearest plausible variable.

${ }^{8}$ Balance tests and additional robustness tests, reported in the Appendix, do not affect our final inferences. In robustness tests, we also control for region.
} 
May.

Whist our quasi-experimental design relies on data from only one of the five intervened-in countries, Portugal is case which is likely to wield external validity. Portugal represents neither an extreme example of intervention nor a contested case. The interventionist actions taken by the Troika in Greece can be viewed as an extreme example of intervention given the repeated need of external actors to provide financial rescue packages - each laced with their own conditionalities - on numerous occasions over a significant period of time. These repeated interventionist actions were not observed in the other intervened-in states. At the same time, there is consensus over Portugal's status as an intervened-in economy. Despite Spain signing a Memorandum of Understanding with the EU's financial institutions in 2012, there is domestic contention over whether or not this financial transfer equates to a "bailout" or not (Magone, 2016). The same is true of Italy: whilst some studies include the actions of the ECB's communication with Italy as tantamount to intervention (Ruiz-Rufino \& Alonso, 2017) others do not (Devine, 2019; Schraff \& Schimmelfennig, 2019). As such Portugal represents a "perfect pupil" (Magone, 2014) example of intervention. It is therefore a case where the theorised effects should be observed.

In addition, whilst there may be questions over how exogenous this treatment was, ${ }^{9}$ we assume that whilst the potential for being bailed out existed before, the date and exact content of the bailout program would not have been known before the 16th May. Moreover whilst prior to the intervention announcement citizens may have held pessimistic assessments of the current economic situation, our theoretical expectations are primarily concerned with prospective evaluations where intervention cues citizens that Troika-solicited austerity measures will shape economic conditions in the near future as

\footnotetext{
${ }^{9}$ In line with the arguments made by Alonso (2014), we also posit that receiving an intervention from the EU is not solely determined by uniquely economic predictors. Whereas in the case of Ireland and Spain, intervention was required because of a struggling banking sector, weak political institutions, and government miscalculations played an important role in the case of Greece. Intervention also represents a politically-motivated decision on behalf of the financiers who have their own (domestic) political \& economic incentives (see, for example, Schneider (2019), and Schneider and Tobin (2020) and Bernhard and Leblang (2016)).
} 
well as update perceptions of the current economic situation. Empirically, we also observe an increasing trend in political support and economic expectations, and no trend in economic evaluations, during the pre-treatment period (presented in Figure A2). This makes our findings of a negative effect even more significant. The data, therefore, confirms our expectation that the results are not part of an ongoing trend during the fieldwork; if anything, the treatment reversed an otherwise positive trend.

To answer $\mathrm{H} 1$ and $\mathrm{H} 2$, we use three outcome variables. We use the dichotomous measure of whether the respondent 'tends to trust' (1) or 'tends not to trust' (0) the country's national parliament for H1. We unfortunately cannot also test for democratic satisfaction, as this is not included in the dataset. For H2, we use two indicators of economic perceptions. First, we use one of 'economic evaluations', which indicates how the respondent thinks the national economy is doing, on a four-point scale from 'very good' to 'very bad'. Second, we use one of economic expectations (or prospective evaluations) which asks how the economy is expected to do in the next twelve months, on a threepoint scale indicating 'better', 'worse', or 'the same'. ${ }^{10}$ All of these retain the original coding in the survey; however, we reverse the coding of economic evaluations from the raw data so that the responses run from negative to positive evaluations and recode the economic expectations so that 'the same' is the middle category. This is only to make the interpretation of coefficients more intuitive. Full question wordings and descriptive statistics are provided in the appendix.

Each of our model specifications in our quasi-experimental test rely on linear regression, the results of which are presented in Figure 1. The results show that the intervention had a significant impact on trust in parliament and economic evaluations at the $95 \%$ level and on economic expectations at the $99 \%$ level. For trust, this amounts to a 6.8 percentagepoint decrease in the probability of trusting parliament. Considering the mean is $27 \%$, this is a substantively large change relative to the overall probability $(-25 \%$ relative to the

\footnotetext{
${ }^{10}$ In the appendix and robustness tests, we also use an 'index' measure which combines them both. This is provided in the raw Eurobarometer data, which combines the previous two to create respondents which are, for instance, 'anxious and pessimistic' - those who see the situation as very bad and getting worse.
} 
sample mean). For economic evaluations, the expected change is -.11 on a $1-4$ scale $(2.8 \%$ of the total, $19 \%$ of a standard deviation); and for economic expectations, the expected change is -.17 on a $1-3$ scale $(5.6 \%, 27 \%$ of a standard deviation).

This is how the average citizens' economic perceptions and levels of political support have been affected by the intervention shock. It is of course possible that this effect is moderated by variables such as partisanship. That said, we expect trust in parliament (as opposed to trust in government) to be less influenced by partisanship. In the case of Portugal, the mainstream left and right parties were both involved in the process of EU intervention. The Sócrates-led Socialist government engaged in initial talks with the Troika institutions in May 2011 and the EU-demanded reforms were adopted via the approval of the Coelho-led coalition government of centre-right parties. Importantly, the socialists abstained in the vote with only the hard-left voting against. Effectively, all mainstream parties were complicit in the introduction of EU intervention (Fernandes et al., 2018). ${ }^{11}$ Whilst we are unable to test for the potential moderating effect of partisanship due to the absence of any relevant variables in the Eurobarometer dataset, Okolikj and Hooghe (2020) show that during the same time period in Europe, partisanship exhibited only a very minor effect in biasing individual's economic evaluations with government-supporting and opposition-supporting voters changing their perceptions of economic performance largely symmetrically. It is also important to note that the average effect on the population as a whole is substantive.

This caveat aside, these results indicate that intervention had an immediate and sizable impact on trust in parliament, evaluations of the current state and expectations of the future performance of the economy. The effect is twice as large on economic expectations as evaluations, indicating that of relatively more importance is the updating of how the economy is expected to perform rather than how bad it currently is. This suggests that the updating of economic priors is not necessarily about the current state of the economy

\footnotetext{
${ }^{11}$ It is for this reason that we also present the null effect of intervention on trust in government in appendix table A5; whilst this does caveat our results, we are cautious given the high chance of partisan reasoning and our inability to test or control for that possibility.
} 


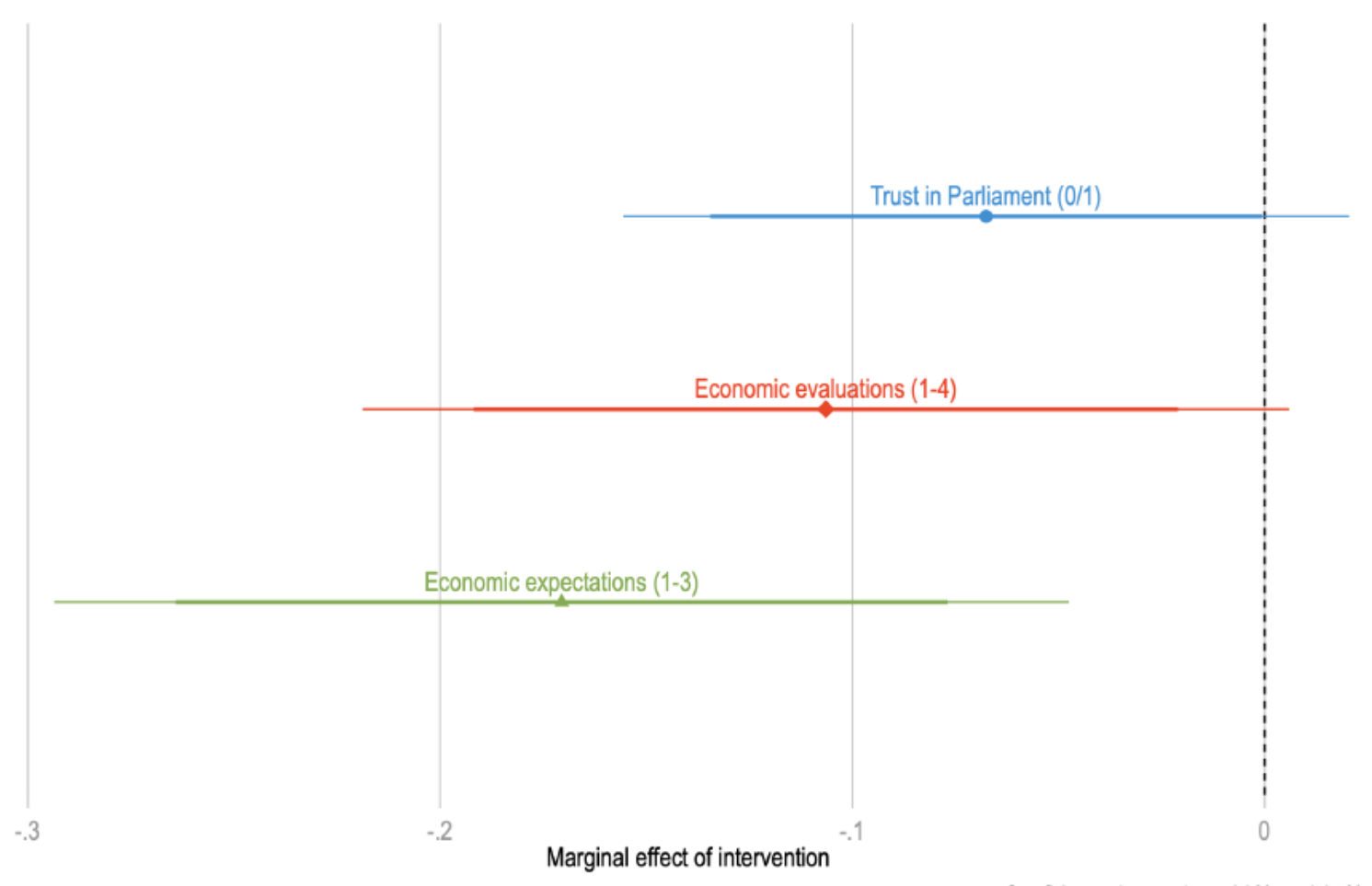

Confidence intervals at $99 \%$ and $95 \%$

Figure 1: Marginal effect of intervention on trust and economic views

- since most will likely have more important and direct sources of information, such as income or employment - but rather that current conditions are not likely to improve any time soon. These results support $\mathrm{H} 1$ and $\mathrm{H} 2$, showing that the randomly allocated exposure to news regarding intervention has a negative effect on both political support and economic perceptions.

We provide robustness and sensitivity tests for the assumptions regarding, amongst other concerns, excludability, ignorability and spurious time trends (Muñoz et al., 2020). We cater to each of these concerns in turn. First, we reduce the bandwidth to three days either side of the intervention to rule out time trends and the influence of hard-to-reach groups which are surveyed at the end of fieldwork. Second, we construct a number of placebo dates, such as the median date of the control group (including and excluding the treated individuals) and the 5th and 6th days of fieldwork. We complement this with randomisation inference by conducting a permutation test, which reproduces the analysis by randomly assigning the 'treatment' date to any of the dates in the survey: 
from 1,000 iterations, the placebo effects are normally distributed around zero. Third, we change the unit of analysis to all twenty-eight then-member states and show that there are no significant negative effects in any other countries. ${ }^{12}$ Fourth, the treatment date is only significant for our outcome of interest. Finally, we implement nearest-neighbour matching with a range of specifications. Whilst these results at times lose significance due to the reduced sample size, the point-estimates are almost always identical to our reported result. The full output and discussions of these tests are reported in the appendix.

The results of our quasi-experimental analysis are important for establishing the plausibility of a causal effect of the interventions on support and economic perceptions, an issue which has previously been unstudied at the individual level (Schraff \& Schimmelfennig, 2019). However, we improve the generalisability of this precise causal estimation in the next section by broadening our model to all countries in the European Union and isolating the mechanism through which the interventions operated.

\section{Study 2: Mediation analysis}

The section that follows applies generalised simultaneous equation modelling (GSEM) in order to carry out a mediation analysis. Relying on the aggregate level Eurobarometer data from all EU countries between 2005 and 2015 (see Table A8 for survey waves included in analysis), we model simultaneous equations that estimate the impact of intervention on satisfaction with democracy (SWD). SWD is measured via a four-point scale indicating those who are 'Not at all satisfied' (1) to 'Very satisfied' (4). The mediating variable of interest, subjective economic perceptions, is measured in a similar four-point fashion, indicating those who believe the economic situation in their country is 'Very bad' (1) to 'Very good' (4).

The primary explanatory variable capturing intervention is a dichotomous indicator for

\footnotetext{
${ }^{12}$ Malta is an exception. There are 57 individuals interviewed after the treatment date in Malta. There is no reason to suspect there are spillover effects or some variable which links these two countries. One possible explanation for the negative effect observed here may be the result the announcement of industrial strike action in Malta on May 17 th.
} 
the country-years in which a member state was intervened. This operationalisation replicates that prevalent in the literature (Ruiz-Rufino \& Alonso, 2017; Schraff \& Schimmelfennig, 2019; Turnbull-Dugarte, 2020b) and includes Greece and Ireland post-2010, Portugal post-2011, Spain post-2012 and Cyprus post-2013. ${ }^{13}$ We do not include Italy in the main intervention model since it was not a formal signatory of a Memorandum of Understanding. Including Italy (post-2011) - and other states in receipt of economic bailout packages before the Eurozone crisis - in the intervention group does not alter the main findings (see Figure A12 and Figures A14-A15).

As in the case of the quasi-experimental design, we present our mediation analysis via the potential outcomes framework (Imai et al., 2011; Imai et al., 2010b). The purpose of the mediation analysis is to assess how much of the treatment effect of intervention $(T)$ on our potential outcome, SWD $(Y)$, is caused by updates in perceptions of economic performance $(M)$. We estimate three parameters: the average total effect (ATE), the average mediated effect (AME), and the average direct effect (ADE) of the EU's economic intervention on political support. The ATE represents all of the variation in SWD that can be explained by EU intervention and is equal to the sum of the ADE and AME (Imai et al., 2010a, p. 312; Imai et al., 2011, p. 769).

The total effect can be defined as $\mathrm{TE}=\mathrm{SWD}_{c, t}(\mathrm{~T}(1))-\mathrm{SWD}_{c, t}(\mathrm{~T}(0))$, where $T$ indicates that a country $(c)$ was exposed to EU intervention at time $(t)$. Obviously for a single data point both $T(1)$ and $T(0)$ cannot be observed so the ATE relies on the average difference in means between units exposed to treatment (intervention) and those not.

We are interested in deconstructing the ATE into its distinct components: $A M E+A D E$. The AME is indicative of the impact of EU intervention that is mediated by changes

\footnotetext{
${ }^{13}$ Our operationalisation of intervention assumes a simple pre-post threshold in those states where intervention is applied. The financial monitoring programs imposed by the EU were temporary however and, as a result, one can make the case that a more time-sensitive operarionalisation would indicate intervention as those only time-years were EU-imposed constraints were formally imposed. An alternative means of indicating intervention that considers each intervened-in states' exit from the program - Ireland (December 2013), Portugal (May 2014), Spain (January 2014) - is reported in the appendix (Figure A19). The results demonstrate identical effects in terms of the mediation although the overall average effect of intervention is slightly smaller.
} 
in perceived economic conditions. Since economic evaluations $(M)$ can be updated by exposure to intervention, there will be two potential values: $M_{c, t}(1)$ when economic perceptions are exposed to treatment $(T=1)$ and $M_{c, t}(0)$ when economic intervention is absent $(T=0)$. The ME measures the variation in SWD caused by alterations in the value of the mediating variable if the value of treatment was held constant. $S W D c, t(T, M(1))$ indicates the outcome variable when exposed to intervention $T(1)$, whilst $S W D_{c, t}(T$, $M(0))$ indicates the outcome variable when $T(1)$ but the value of the mediating variable has the $\mathrm{M}$ value when $T(0)$. The AME indicates the variation in SWD caused by a unit change in economic perceptions that was brought about by intervention whilst also considering the direct effect of intervention on SWD. ${ }^{14}$ If intervention exhibits no effect on subjective economic evaluations (i.e. $M(1)=M(0)$ ), the mediation effect is equal to zero (Imai et al., 2010a, p. 311) and this would indicate that intervention does not operate via the economic cues thesis but rather other mechanisms. Formally, the mediation effect can be summarised as $M E=S W D_{c, t}(T, M(1))-S W D_{c, t}(T, M(0))$.

Finally, the ADE represents the variation in SWD that can be explained by all other alternative channels that link EU intervention to political support, such as the reduced manoeuvrability or 'democracy without choice' thesis (Alonso, 2014). The direct effect is formalised as: $D E=S W D_{c, t}(T(1), M(T))-S W D_{c, t}(T(0), M(T))$. This indicates the impact of intervention on SWD whilst holding the effect of economic perceptions constant. The ADE indicates the average effect of intervention on SWD that is not explained via mediation through subjective evaluations of the economy.

Given the variables available in the data, we are only able to provide a concrete test of the mediation caused by the economic updating hypothesis. The remaining influence of intervention once the mediating effect of subjective economic performance is considered, the ADE, captures all remaining avenues of influence. Given the theorised mechanisms, we can assume that the ADE is capturing the influence of the reduced manoeuvrability

\footnotetext{
${ }^{14}$ Note the distinction here from the instrumental variable (IV) approach. While IV models assume that the IV has no effect on the outcome of interest, the mediation analysis we adopt here accommodates for a direct effect between intervention and SWD (Imai et al., 2010b)
} 
thesis as well as other potentially unaccounted for avenues. The model controls for objective economic performance, country fixed effects and time trends. ${ }^{15}$

Figure 2 displays the key coefficients of the models of our two equations as a causal path diagram. The full output is reported in the appendix (see Table A16). The coefficients displayed in the figure illustrate the effect of EU intervention and changes in unemployment on both economic evaluations and SWD. The unemployment rate captures the country-level $(\%)$ change in unemployment between time $t$ and the year prior $(t-1)$. Unemployment is taken as the main indicator of objective economic conditions alongside intervention although other measures of macroeconomic performance are also considered (see Figure 4). We take this to be the strictest test, since unemployment is the indicator most closely related to the lived economic experiences of individual citizens (unlike, for instance, changes in GDP). The model displays a significant direct effect of intervention on economic evaluations and SWD. In the case of the macroeconomic control, however, the results show that the changes in unemployment effect economic evaluations but not satisfaction with democracy. This suggests that any effect of unemployment on our core dependent variable is mediated through its effect on economic evaluations. To demonstrate this, we turn to the results of the mediation analysis presented in Figure 3 . The illustration shows the ATE, AME and the ADE of exposure to EU intervention and a one percentage-point increase in the unemployment rate on SWD.

As expected, the total effect of both intervention and unemployment is significant and negative. Exposure to intervention is associated with a sizeable and significant decrease in SWD as too is an increase in unemployment. Compare the effects of intervention to that of changes in unemployment. First, there is a clear difference in magnitude. Whilst the ATE of both intervention and changes in unemployment exhibit a significant effect on SWD, the substantive effect of intervention is notably greater. The level of SWD in countries undergoing intervention is, on average, .44 lower. The average value of SWD

\footnotetext{
${ }^{15}$ We use two-tailed hypothesis tests throughout (alpha $=0.05 \&$ alpha $=0.01$ ), applying robust standard errors. Estimations using country-clustered standard errors do not change the findings (see appendix table A17).
} 


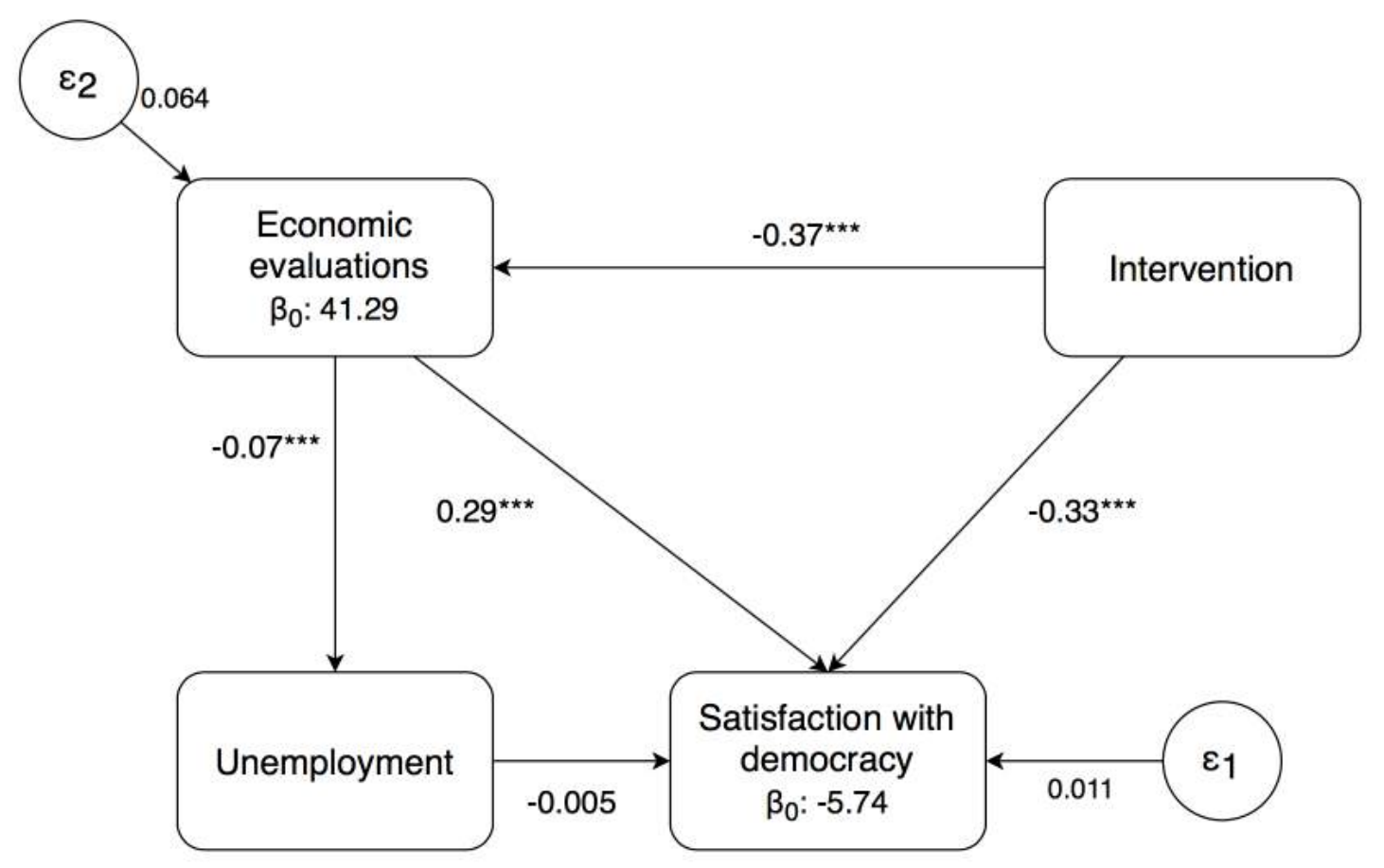

Country and year fixed effects included but not shown.

${ }^{+} p<0.1,{ }^{*} p<0.05,{ }^{* \star} p<0.01,{ }^{* \star *} p<0.001$

Figure 2: Causal path diagram of the generalised structural equation models 


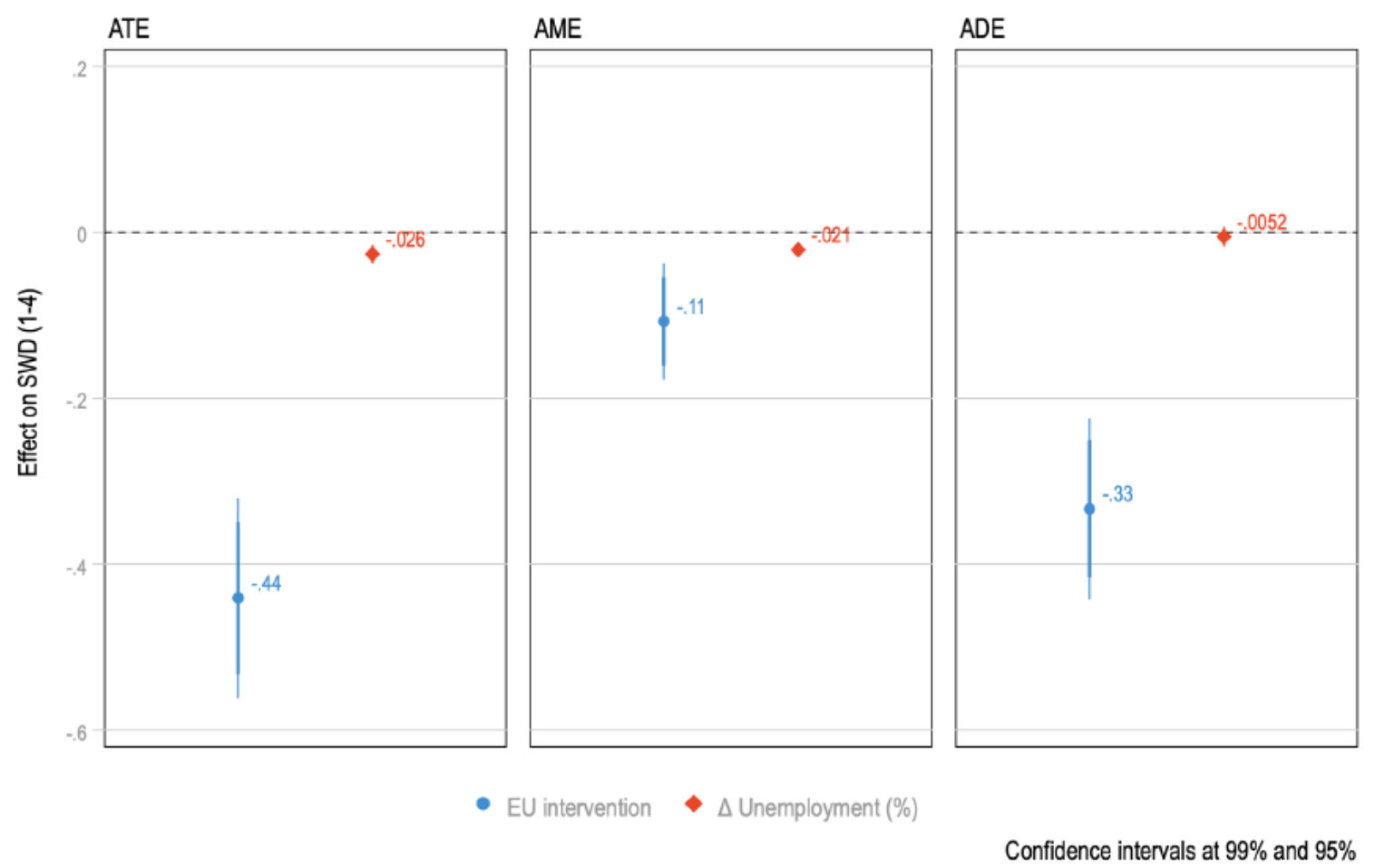

Figure 3: Direct, indirect and total effect on SWD

(scaled 1-4) in the sample is 2.46 so a .44 change is a notable effect size (11\% of the total, or $113 \%$ of a standard deviation). A one percentage-point increase in unemployment is associated with a .026 decrease in SWD. As an illustration, Greece experienced an increase in the unemployment rate between 2011 and 2012 of close to seven percentagepoints. Taking the ATE of unemployment, this seven percentage-point change would translate into a 0.18 decrease in SWD which equates to $4.6 \%$ of the total or $46.67 \%$ of a standard deviation.

Beyond the effect of intervention and taking changes in unemployment as an indicator of macroeconomic performance, it is clear that the relationship between unemployment and SWD is entirely mediated by updates in citizens' perception of the state of the economy. Recall that the AME indicates the internal value of the total effect that is explained via updates in economic perceptions. The AME of unemployment is significant and negative, whereas the ADE (that which captures the direct effect of changes in unemployment) is indistinguishable from zero. In other words, there is no other avenue for the effect of 
objective economic performance (unemployment) on SWD once the impact such changes have on economic perceptions is considered. In the case of EU intervention on the other hand, there is a clear direct effect on SWD. Even when considering the impact that intervention has on political support as a result of changes in subjective assessments of the economy, EU intervention leads (directly or through other mechanisms) to a sizeable decline in SWD.

Importantly, the mediated effect of changes in the unemployment rate are echoed across alternative operationalisations of objective economic performance. Figure 4 depicts the ATE, AME and ADE of changes in the budget deficit, public debt, or government borrowing rates, which are used as substitute indicators in the place of changes in unemployment in a step-wise fashion. In terms of their effect on political support once taking into account the impact of intervention, only changes in the level of unemployment and public debt have any non-zero effect on SWD, whereas changes in the budget deficit or government borrowing rates don't have any impact. The null effect in the case of the cost of borrowing is of note given that the fiscal flexibility of the state is often constrained by the accessibility of the state purse to access liquidity on the financial markets. Whilst interest rates might be a measure of objective manoeuvrability, the lack of any effect on SWD suggests that any correlation between state access to capital on the financial markets is not an economic signal that citizens rely on to update their prior understanding of the state of politics in the country. ${ }^{16}$

As in the case of the unemployment rate, the significant negative effect of government debt on political support appears to be entirely mediated by updates in citizens' perception of the economy. The ADE is indistinguishable from zero once the impact of debt on subjective evaluations is considered. This is largely consistent with Becher and Donnelly (2013), who show that objective economic conditions affect voting behaviour via the

\footnotetext{
${ }^{16}$ We consider additional controls in the Appendix including changes in GDP growth, changes in nominal labour costs as well as the Kriesi (2016)'s misery index (Figure A13). Kriesi's misery index, which has been used in other studies focused on the Eurozone crisis (see (Kriesi \& Pappas, 2015; TurnbullDugarte, 2020a), is computed via an explanatory factor analysis of changes in GDP, unemployment and government debt (Cronbach $\alpha=0.65$ ). Larger values are indicative of greater economic malaise. Our results are unchanged across these alternative specifications.
} 


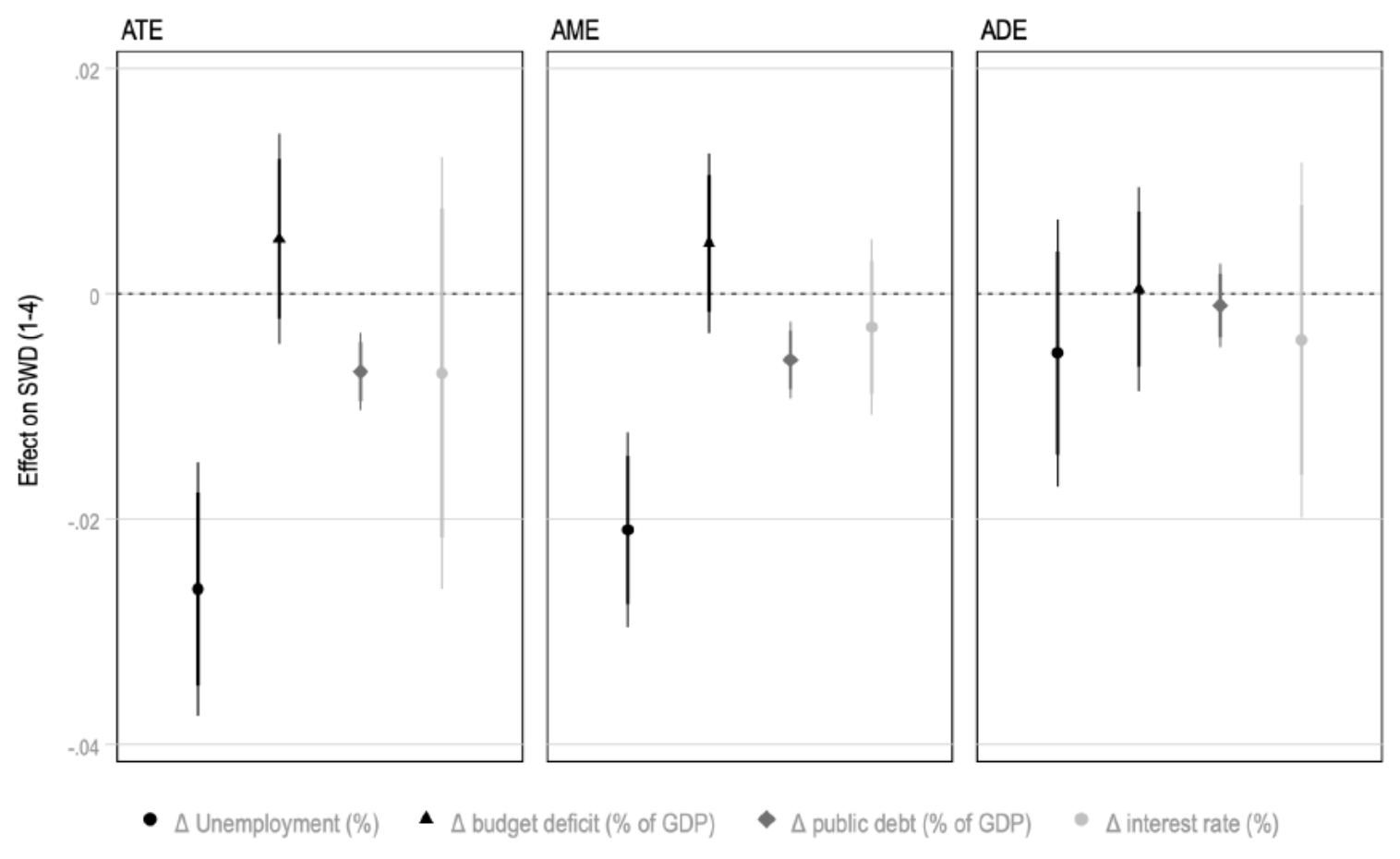

Confidence intervals at $99 \%$ and $95 \%$

Figure 4: Comparing mediation effects

mediated impact they have on citizens' subjective evaluation of the state of the economy. The results we present here suggest that the role of economic conditions in shaping citizens' level of SWD operates in a similar fashion. This reconciles existing work which debates whether support is driven by perceptions or conditions; we argue both, but that economic conditions work through perceptions rather than via a direct effect. Once the indirect effects of each of our macroeconomic variables are considered, none of them exhibit an independent direct effect on SWD. This is notably different from the effect of economic intervention. Across all of the model specifications using different alternatives to operationalise objective economic malaise, the independent ADE of EU intervention retains its significant negative effect. As a result, we are confident that intervention exhibits an important direct effect on political support beyond that which is mediated by subjective evaluations regarding the state of the economy.

To ensure the robustness of our findings related to intervention, we carry out three additional sensitivity tests. First, we estimate a jackknife test removing each intervened-in 
country from the sample in a step-wise manner (Figure A12). Our results from this test are twofold. Firstly, we observe that the negative effects of intervention from a single country are not influencing the overall results. Secondly, this provides greater external validity to our quasi-experimental test in Portugal: the effects are similar in all scenarios. Second, we re-estimate our main model to include a control indicating the country-years during which a country held a legislative or presidential election. Elections, as windows of opportunity for voters to exercise political choice and trigger alternations in government, can increase political support. The country-years in which elections took place could therefore have impacted the relationship between EU intervention and SWD. Including this in our model, however, shows that this is not the case, with our findings remaining unchanged. Third, we replicate the mediation analysis on the individual-level data from Portugal (Figure A20). As in the case of our cross-national analysis, we observe that around one third of intervention's effect on political trust is mediated via economic evaluations, whereas the remaining effect of intervention operates via alternative mechanisms, amongst which, we can assume are concerns regarding state manoeuvrability.

In real terms our results provide mixed evidence in support of H3. On the one hand, we find that a noteworthy proportion of intervention's effect on political support is mediated by economic evaluations. This suggests that intervention serves, as we hypothesised and in line with the economic cue thesis, as an information shock that updates citizens' priors regarding the current and future performance of the economy. On the other hand, however, and unlike the objective performance indicators, a large(r) part of the variation in political support explained by intervention occurs because of mechanisms other than the economic cue thesis. Unfortunately, it is not possible to test these other mechanisms due to data limitations. We expand on this in the following section. 


\section{Discussion}

Our contributions are threefold. Firstly, as expected and in line with H1, we provide causal evidence that exposure to economic intervention leads to a negative effect on political support. Taking advantage of the quasi-experimental nature of information shocks regarding the EU's intervention in Portugal, we find an average treatment effect of seven percentage-points. Secondly, we similarly show that interventions also had a negative causal impact on economic evaluations. Citizens who were informed ${ }^{17}$ of the press release regarding the EU's pending intervention in the country were between $17 \%$ and $33 \%$ of a standard deviation more negative about the economy, both how it is currently performing or how it is expected to perform in the future. The effect on prospective evaluations was found to be approximately twice as large as current evaluations, suggesting that the intervention signalled that the bad times were here to stay rather than colouring perceptions of present-day economic conditions. These findings are consistent with the existing literature (Devine, 2019; Ruiz-Rufino \& Alonso, 2017), yet contributes the closest approach to causality so far and fills the 'uncharted territory' at the individual level (Schraff \& Schimmelfennig, 2019).

Thirdly, we provide nuance to the debate about the political or economic - or input versus output - determinants of political support by showing that the negative consequences of the EU's fiscal monitoring programmes on political support cannot be entirely accounted for by updates in economic evaluations (Foster \& Frieden, 2017; Scharpf, 1999). Relying on the aggregate data of the cumulative waves of the Eurobarometer, we find that the link between objective economic conditions and political support is entirely mediated via updates in individuals' subjective view of the economy, but that only a third of the effect of the Eurozone's bailout packages is. This suggests that whilst the overall effect of economic conditions is large, it cannot explain the effect of interventions on its own. Rather, the effect is a combination of this and also other factors that we cannot test

\footnotetext{
${ }^{17}$ Recall that the estimand of interest is the intent-to-treat (ITT) effect as opposed to the complier average causal effect (CACE) given that we are unable to ascertain those individuals who actually read or heard about the bailout
} 
here. Given one theorised link between economic intervention and political support is the room to manoeuvre thesis, we would expect this to matter as well. Whilst we test for this using aggregate indicators such as debt and interest rates, which are commonly used in the literature, and show null effects, we are cautious of interpreting this too much given the lack of individual-level data to test causality and to separate it from general economic conditions. However, there are also other potential mechanisms: did the intervention update citizens' views about corruption or clientilism, for instance? Of course, there will be some amount of the variation that is just noise and error.

These findings have significant contributions beyond this specific context. Our finding that the effect of economic conditions on political support is entirely mediated by economic evaluations reconciles the literature in political support which has wrestled with whether economic conditions matter, with some arguing that it is almost the only factor that matters (e.g Foster \& Frieden, 2017; Quaranta \& Martini, 2016; Stimson, 2004), whether it is about perceptions (Armingeon \& Guthmann, 2014), and how these may be moderated by institutional context. Our results support the notion, emerging within the support literature, that conditions are only relevant through their effect on economic perceptions (see also Christmann, 2018). It is worth noting that both our study and Christmann (2018) arrive at the same conclusion with different datasets and analytical techniques. Whilst we don't test institutional effects, this suggests that institutions are relevant at least in part through facilitating the (accurate) linking of conditions to evaluations, in much the same way that institutions link economic conditions to voting behaviour (Kayser, 2007; Powell, 2000).

Political support is often theorised as the outcome of input factors and output factors (Scharpf, 1999). The former refers to rule by the people, and the latter to state or government effectiveness (rule for the people). The bulk of the literature spends considerable time reasoning between these factors and how they condition each other (Dahlberg et al., 2015; Magalhães, 2016). The economic interventions in Europe during the Eurozone crisis present an ideal setting to study this, given the significant institutional and eco- 
nomic transformations. What our results show is that researchers would be remiss to dismiss support for institutions as a function of (economic) outputs. Whilst we can't quantify the importance of input factors, we have shown that economic factors cannot account for all, or even most, of political support.

Finally, the interventions are a case of external economic shocks. Research has studied the effect of these for mass politics, and more broadly how interdependence shapes individual attitudes and behaviour (Ahlquist et al., 2020; Arel-Bundock et al., 2019; Kayser \& Peress, 2012). We have provided evidence that external economic shocks do indeed have significant repercussions; alongside the implications for voting behaviour and concomitant rise of challenger parties and reshaping of party politics we again find that it also matters at the more diffuse level of institutional support. Moreover, this implies that citizens do take cues from externalities, and are not bound to domestic factors. 


\section{References}

Ahlquist, J., Copelovitch, M. \& Walter, S. (2020). The Political Consequences of External Economic Shocks: Evidence from Poland. American Journal of Political Science, Online Fir.

Alonso, S. (2014). You can vote but you cannot choose: Democracy and the Sovereign Debt Crisis in the Eurozone, Instituto Carlos III - Juan March de Ciencias Sociales.

Alonso, S. \& Sánchez-Cuenca, I. (2020). EU intervention vs. national autonomy: do citizens really care? European Politics and Society, Online Fir.

and Schneider, C. J. \& Tobin, J. L. (2020). The Political Economy of Bilateral Bailouts. International Organization, 74, 1-29.

Arel-Bundock, V., Blais, A. \& Dassonneville, R. (2019). Do Voters Benchmark Economic Performance? British Journal of Political Science, EarlyView.

Armingeon, K. \& Guthmann, K. (2014). Democracy in crisis? The declining support for national democracy in European countries, 2007-2011. European Journal of Political Research, 53(3), 423-442.

Armingeon, K., Guthmann, K. \& Weisstanner, D. (2016). How the Euro divides the union: The effect of economic adjustment on support for democracy in Europe. Socio-Economic Review, 14(1), 1-26.

Becher, M. \& Donnelly, M. (2013). Economic performance, individual evaluations, and the vote: Investigating the causal mechanism. Journal of Politics, 75 (4), 968-979.

Bernhard, W. T. \& Leblang, D. (2016). Sovereign Debt, Migration Pressure, and Government Survival. Comparative Political Studies, 49(7), 907-938.

Blyth, M. (2013). Austerity: The History of a Dangerous Idea. Oxford University Press.

Christmann, P. (2018). Economic performance, quality of democracy and satisfaction with democracy. Electoral Studies, 53, 79-89.

Cordero, G. \& Simón, P. (2016). Economic Crisis and Support for Democracy in Europe. West European Politics, 39(2), 305-325. 
Dahlberg, S., Linde, J. \& Holmberg, S. (2015). Democratic discontent in old and new democracies: Assessing the importance of democratic input and governmental output. Political Studies, 63(S1), 18-37.

Devine, D. (2019). Perceived government autonomy, economic evaluations, and political support during the Eurozone crisis. West European Politics, 44 (2), 229-252.

Duch, R. M. \& Stevenson, R. T. (2008). The economic vote: How political and economic institutions condition election results. Cambridge University Press.

ECOFIN. (2011). Statement by the Eurogroup and ECOFIN Ministers.

Fernandes, J. M., Magalhães, P. C. \& Santana-Pereira, J. (2018). Portugal's Leftist Government: From Sick Man to Poster Boy? South European Society and Politics, $23(4), 503-524$.

Foster, C. \& Frieden, J. (2017). Crisis of trust: Socio-economic determinants of Europeans' confidence in government. European Union Politics, 18(4), 511-535.

Friedrichsen, J. \& Zahn, P. (2014). Political support in hard times: Do people care about national welfare? European Journal of Political Economy, 35, 23-37.

Heldt, E. C. \& Mueller, T. (2020). The (self-)empowerment of the European Central Bank during the sovereign debt crisis. Journal of European Integration, EarlyView.

Huebscher, E., Sattler, T. \& Wagner, M. (2020). Voter Responses to Fiscal Austerity. British Journal of Political Science, Online Fir.

Imai, K., Keele, L. \& Tingley, D. (2010a). A General Approach to Causal Mediation Analysis. Psychological Methods, 15(4), 309-334.

Imai, K., Keele, L., Tingley, D. \& Yamamoto, T. (2011). Unpacking the black box of causality: Learning about causal mechanisms from experimental and observational studies. American Political Science Review, 105(4), 765-789.

Imai, K., Keele, L. \& Yamamoto, T. (2010b). Identification, inference and sensitivity analysis for causal mediation effects. Statistical Science, 25(1), 51-71.

Javier, P. (2014). Economic Crisis, Political Legitimacy, and Social Cohesion. Economic crisis, quality of work, and social integration. 
Katsanidou, A. \& Otjes, S. (2015). How the European debt crisis reshaped national political space: The case of Greece. European Union Politics, 17(2), 262-284.

Kayser, M. A. (2007). How domestic is domestic politics? Globalization and elections.

Kayser, M. A. \& Peress, M. (2012). Benchmarking across borders: Electoral accountability and the necessity of comparison.

Kriesi, H. (2016). The Politicization of European Integration. Journal of Common Market Studies, 54, 32-47.

Kriesi, H. \& Pappas, T. S. (2015). European Populism in the Shadow of the Great Recession. ECPR Press.

Laffan, B. (2014). Testing Times: The Growing Primacy of Responsibility in the Euro Area. West European Politics, 37(2), 270-287.

Magalhães, P. C. (2016). Economic Evaluations, Procedural Fairness, and Satisfaction with Democracy. Political Research Quarterly, 69(3), 522-534.

Magone, J. M. (2014). Portugal Is Not Greece: Policy Responses to the Sovereign Debt Crisis and the Consequences for the Portuguese Political Economy. Perspectives on European Politics and Society, 15(3), 346-360.

Magone, J. M. (2016). The politics of Troika avoidance: The case of Spain. Core-periphery relations in the european union: Power and conflict in a dualist political economy. Routledge.

Mair, P. (2013). Ruling the Void: The Hollowing of Western Democracy. Verso.

Morlino, L. \& Quaranta, M. (2016). What is the impact of the economic crisis on democracy? Evidence from Europe. International Political Science Review, 37(5), 618633.

Muñoz, J., Falcó-Gimeno, A. \& Hernández, E. (2020). Unexpected Event during Survey Design: Promise and Pitfalls for Causal Inference. Political Analysis, 28(2), 186206.

Okolikj, M. \& Hooghe, M. (2020). Is there a partisan bias in the perception of the state of the economy? A comparative investigation of European countries, 2002-2016. International Political Science Review, Online Fir. 
Otjes, S. \& Katsanidou, A. (2017). Beyond Kriesiland: EU integration as a super issue after the Eurocrisis. European Journal of Political Research, 56(2), 301-319.

Powell, G. B. (2000). Elections as Instruments of Democracy. Yale University Press.

Quaranta, M. \& Martini, S. (2016). Does the economy really matter for satisfaction with democracy? Longitudinal and cross-country evidence from the European Union. Electoral Studies, 42, 164-174.

Quaranta, M. \& Martini, S. (2017). Easy Come, Easy Go? Economic Performance and Satisfaction with Democracy in Southern Europe in the Last Three Decades. Social Indicators Research, 131(2), 659-680.

Ruiz-Rufino, R. \& Alonso, S. (2017). Democracy without choice: Citizens' perceptions of government autonomy during the Eurozone crisis. European Journal of Political Research, 56(2), 320-345.

Sánchez-Cuenca, I. (2017). From a Deficit of Democracy to a Technocratic Order: The Postcrisis Debate on Europe. Annual Review of Political Science, 20(1), 351-369.

Scharpf, F. W. (1999). Governing in Europe: Effective and democratic? Oxford University Press.

Schmidt, V. A. (2015). Forgotten Democratic Legitimacy: "Governing by the Rules" and "Ruling by the Numbers". In M. Matthijs \& M. Blyth (Eds.), The future of the euro (pp. 90-116). Oxford University Press.

Schneider, C. J. (2019). The Responsive Union. National Elections and European Governance. Cambridge University Press.

Schraff, D. \& Schimmelfennig, F. (2019). Eurozone bailouts and national democracy: Detachment or resilience? European Union Politics, 20(3), 361-383.

Stimson, J. A. (2004). Tides of Consent: How Public Opinion Shapes American Politics. Cambridge University Press.

Torcal, M. (2014). The Decline of Political Trust in Spain and Portugal: Economic Performance or Political Responsiveness? American Behavioral Scientist, 58(12), $1542-1567$. 
Traber, D., Giger, N. \& Häusermann, S. (2018). How economic crises affect political representation: declining party-voter congruence in times of constrained government. West European Politics, 41(5), 1100-1124.

Turnbull-Dugarte, S. J. (2020a). The impact of EU intervention on political parties' politicisation of Europe following the financial crisis. West European Politics, 43(4), 894-918.

Turnbull-Dugarte, S. J. (2020b). Why vote when you cannot choose? EU intervention and political participation in times of constraint. European Union Politics, 21(3), 406-428.

Vowles, J. \& Xezonakis, G. (2016). Globalization and Domestic Politics: Parties,Elections, and Public Opinion. Oxford University Press. 


\section{Appendix}

\section{Quasi-experimental Analysis}

\section{Descriptive statistics}

Tables A1, A2 and A3 present descriptive statistics for the full sample, control group and treatment group respectively. Table A4 shows the frequency of the observations in each group.

Table A1: Summary statistics, full sample

\begin{tabular}{lccccc}
\hline \multicolumn{1}{c}{ Variable } & Mean & Std. Dev. & Min. & Max. & N \\
\hline Trust & 0.269 & 0.444 & 0 & 1 & 996 \\
Treated & 0.234 & 0.423 & 0 & 1 & 1048 \\
Education & 3.75 & 3.425 & 1 & 11 & 1029 \\
Age & 47.709 & 18.6 & 15 & 91 & 1048 \\
Occupation & 5.052 & 2 & 1 & 8 & 1048 \\
Gender & 1.54 & 0.499 & 1 & 2 & 1048 \\
Econ Evaluations & 1.526 & 0.583 & 1 & 4 & 1041 \\
Econ Expect. & 1.413 & 0.638 & 1 & 3 & 984 \\
Econ Index & 1.248 & 0.663 & 1 & 4 & 738 \\
Region & 2.197 & 1.143 & 1 & 5 & 1048 \\
\hline
\end{tabular}

Table A2: Summary statistics, control

\begin{tabular}{lccccc}
\hline \multicolumn{1}{c}{ Variable } & Mean & Std. Dev. & Min. & Max. & N \\
\hline Trust & 0.28 & 0.45 & 0 & 1 & 756 \\
Treated & 0 & 0 & 0 & 0 & 803 \\
Education & 3.607 & 3.389 & 1 & 11 & 789 \\
Age & 50.611 & 18.146 & 15 & 91 & 803 \\
Occupation & 5.072 & 1.979 & 1 & 8 & 803 \\
Gender & 1.57 & 0.495 & 1 & 2 & 803 \\
Econ Evaluations & 1.546 & 0.59 & 1 & 4 & 798 \\
Econ Expect. & 1.441 & 0.662 & 1 & 3 & 753 \\
Econ Index & 1.29 & 0.711 & 1 & 4 & 563 \\
Region & 2.369 & 1.173 & 1 & 5 & 803 \\
\hline
\end{tabular}

Figure A1 shows the number of respondents by each day of fieldwork, with the dashed red line indicating the intervention. To recap, approximately $25 \%$ of respondents are to the right of the dashed line (i.e are 'treated'). 
Table A3: Summary statistics, treatment

\begin{tabular}{lccccc}
\hline \multicolumn{1}{c}{ Variable } & Mean & Std. Dev. & Min. & Max. & N \\
\hline Trust & 0.233 & 0.424 & 0 & 1 & 240 \\
Treated & 1 & 0 & 1 & 1 & 245 \\
Education & 4.221 & 3.506 & 1 & 11 & 240 \\
Age & 38.196 & 16.839 & 15 & 82 & 245 \\
Occupation & 4.984 & 2.072 & 1 & 8 & 245 \\
Gender & 1.441 & 0.498 & 1 & 2 & 245 \\
Econ Evaluations & 1.461 & 0.554 & 1 & 4 & 243 \\
Econ Expect. & 1.32 & 0.545 & 1 & 3 & 231 \\
Econ Index & 1.114 & 0.453 & 1 & 3 & 175 \\
Region & 1.633 & 0.817 & 1 & 4 & 245 \\
\hline
\end{tabular}

Table A4: Frequency table of treatment variable

\begin{tabular}{lrr}
\hline Group & $\mathrm{N}$ & $\%$ \\
\hline Control & 803 & 77 \\
Treated & 245 & 23 \\
Total & 1,048 & 100 \\
\hline
\end{tabular}

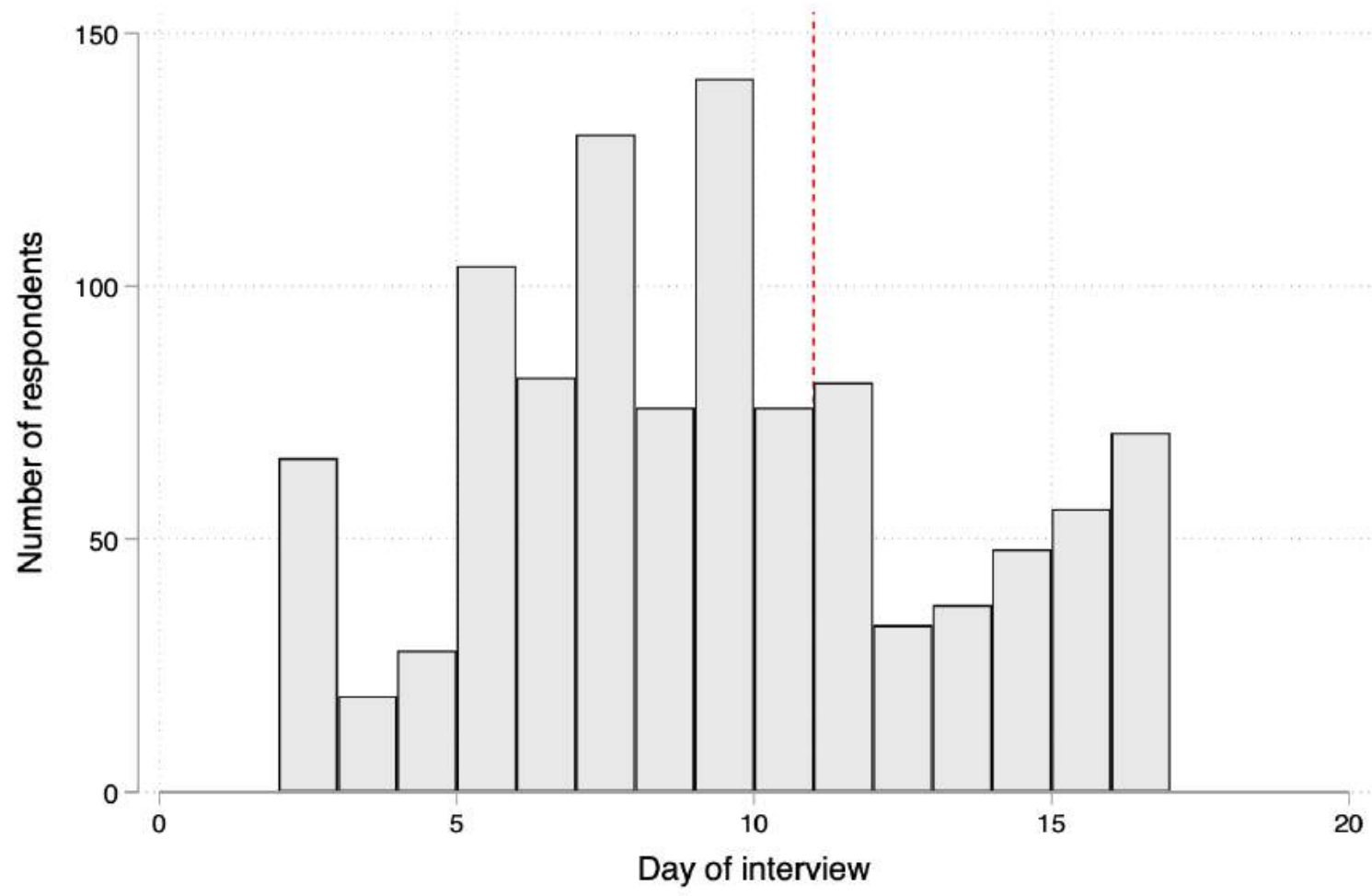

Figure A1: Histogram of number of respondents by day of fieldwork 

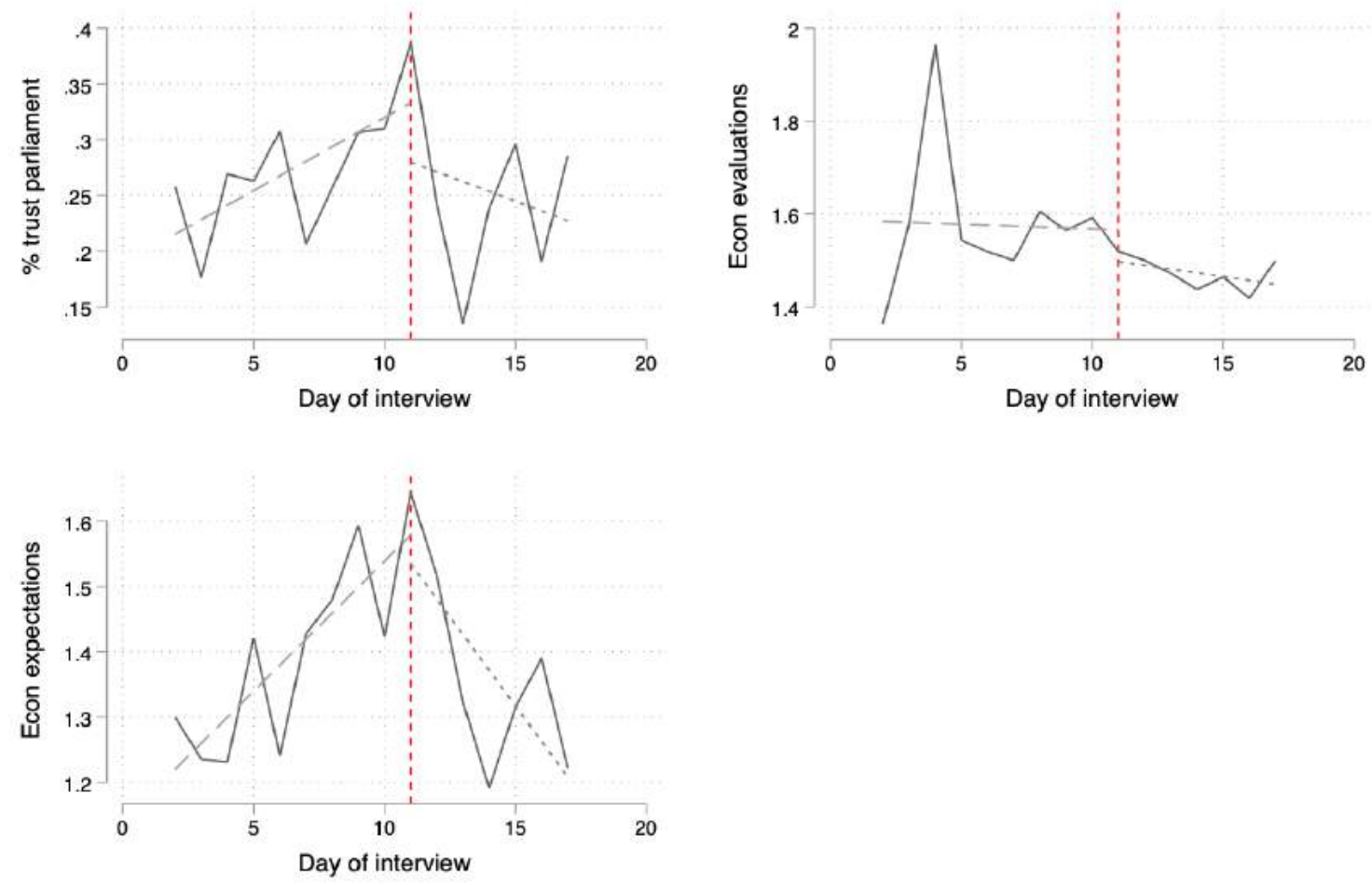

Figure A2: Trends in parliamentary trust, economic evaluations and economic expectations by day of fieldwork

Finally, in figures A2 and A3 we present the trends in mean average levels of those trusting parliament, economic evaluations and economic expectations. In one we fit lines of best fit for pre- and post-trends and in the other we fit the trends with polynomials and confidence intervals. These show that there was no negative trends before intervention, providing support that our analysis is not merely picking up trends. Second, they also show that it is not as if respondents were aware of the upcoming intervention, since it is unlikely that would engender parliamentary trust or improving economic expectations, which is what we see in the descriptive data. 

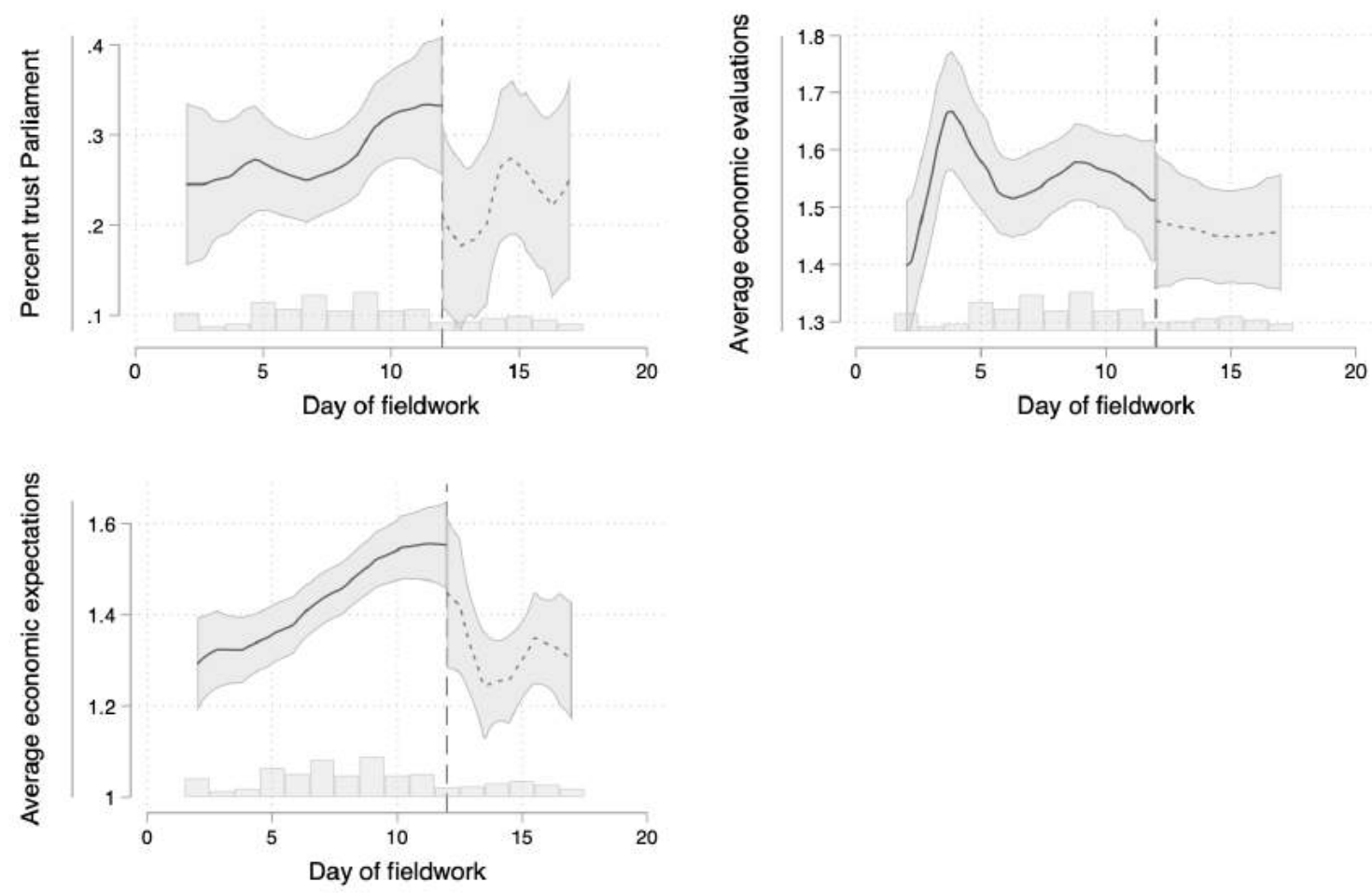

Figure A3: Trends in parliamentary trust, economic evaluations and economic expectations by day of fieldwork, polynomials 


\section{Press coverage of the announcement}

To provide additional evidence of our treatment we searched Factiva, a global news monitoring service provided by Dow Jones, simply for the word "European" (the feminine 'Europeia' in Portuguese, the appropriate inflection for 'European Commission' and 'European Union'). We excluded similar articles. The search indicated that the top organisations listed were the European Central Bank (despite our grammatical choice of 'Europeia'), European Commission, and International Monetary Fund, providing confidence that we received relevant articles. Whilst it is clear that the event was not 'front page' news, it did receive coverage across the political spectrum.

As an example, Publico, a large left-wing daily, reported the following on the 17th of May (the day after the agreement, the day of our treatment) with the title 'no light at the end of the tunnel':

'There are extremely serious measures for citizens in the rescue plan, but there are also proposals that imply facing problems that the political elite has never been able to solve, as it is hostage to interest groups. We are given an opportunity to change, but without being given the choice. ${ }^{\prime 18}$

This type of coverage, reporting on the events in general, continued at least until the 18th of May. Again, similar coverage also appeared in other papers, for instance Jornal de Notícias. The tabloid newspaper Diário de Notícias reported along similar lines, on the day of the 17th of May:

'Yesterday, at the end of the night in Brussels, after leaving the meeting of the Eurogroup that approved the terms of the Portuguese bailout, the Minister of Finance, Fernando Teixeira dos Santos, implied the value of the invoice in interest and also warned that "there are no conditions" for the country to try to review the financial conditions of the

\footnotetext{
${ }^{18}$ In Portuguese: 'Há medidas extremamente gravosas para os cidadãos no plano de resgate, mas há também propostas que implicam enfrentar problemas que o poder político nunca conseguiu resolver, por estar refém dos grupos de interesses. É-nos dada uma oportunidade de mudar, mas sem que nos seja dada a possibilidade de escolher'
} 
loan.' 19

Diário Económico, a leading business and finance newspaper, also reported the events of the previous day. It was reported that 'the loan to Portugal yesterday received the green light from European finance ministers. The European Union yesterday instructed the next Portuguese government to negotiate with its private creditors to convince them not to sell sovereign debt securities.'

It was also reported by international news organisations in Portuguese, such as Reuters, on the 16th of May following the announcement.

\footnotetext{
${ }^{19}$ ' Ontem, ao final da noite em Bruxelas, à saída da reunião do Eurogrupo que aprovou os termos do resgate português, o ministro das Finanças, Fernando Teixeira dos Santos, deixou implícito o valor da factura em juros e avisou ainda que "não há condições" para que o País tente rever as condições financeiras do empréstimo.'
} 


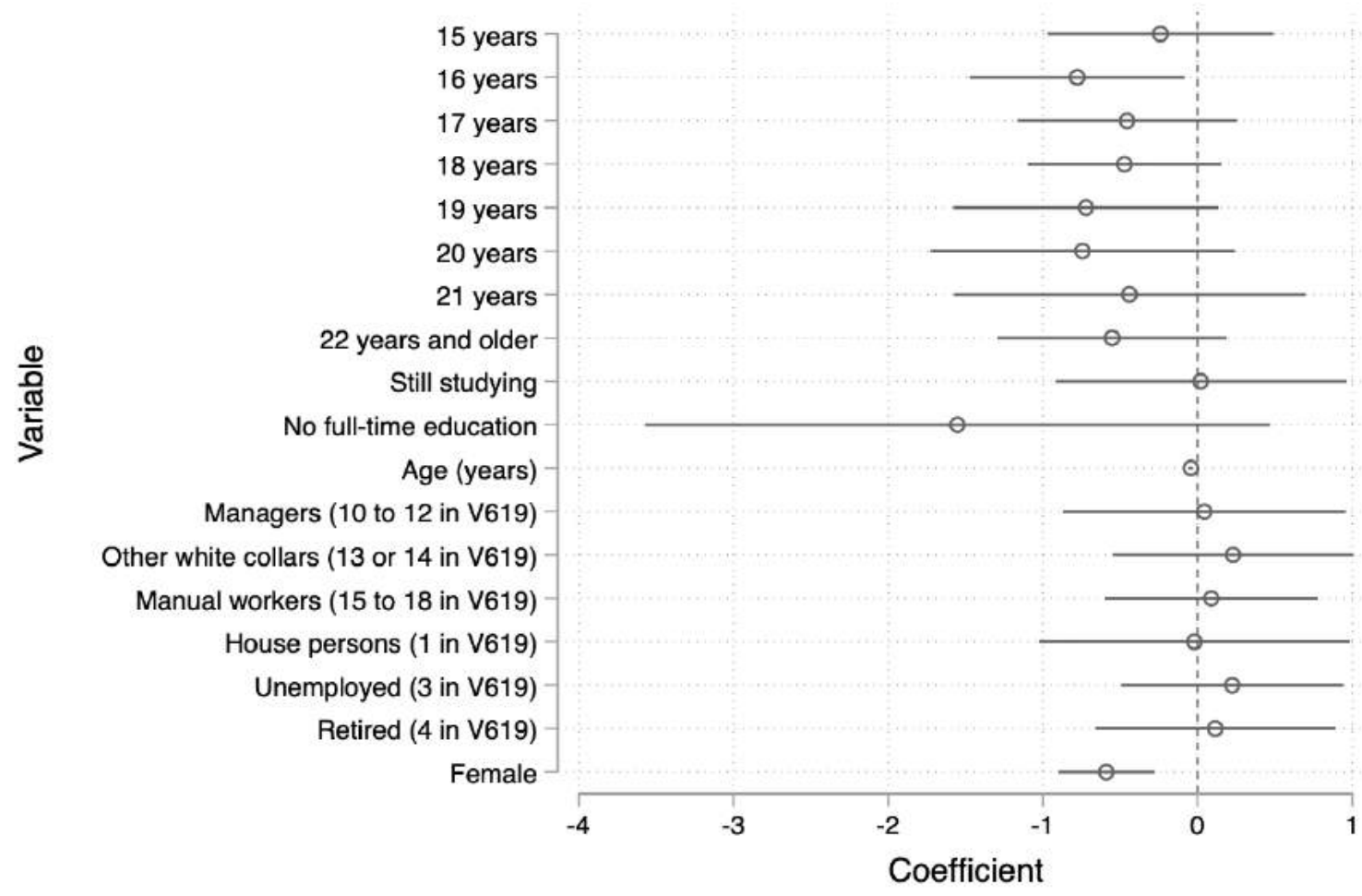

Figure A4: Coefficient for variables predicting treatment assignment

\section{Balance tests and robustness}

The descriptive tables do not show major issues for a balanced sample between treated and controlled, particularly since we control for these demographics. However, to address this, we regress the demographics (education, age, gender and occupation) on the treatment indicator; the coefficients are presented in figure A4. They indicate few concerns except for gender: women are more represented in the control group.

To ensure this does not affect our main inferences, we then run the same models on men and women separately. The results are presented in figure A5. Whilst significance for women is affected in the case of trust in parliament, the coefficients are in the same direction and all others remain unaffected. Significance is a function of sample size; the number of 'treated' females is just 108, and so our power is not sufficient to detect an effect. Given that our matching tests (figures A9 to A11) and all other robustness tests are supportive of our final inferences, we consider this minor deviation not an important 


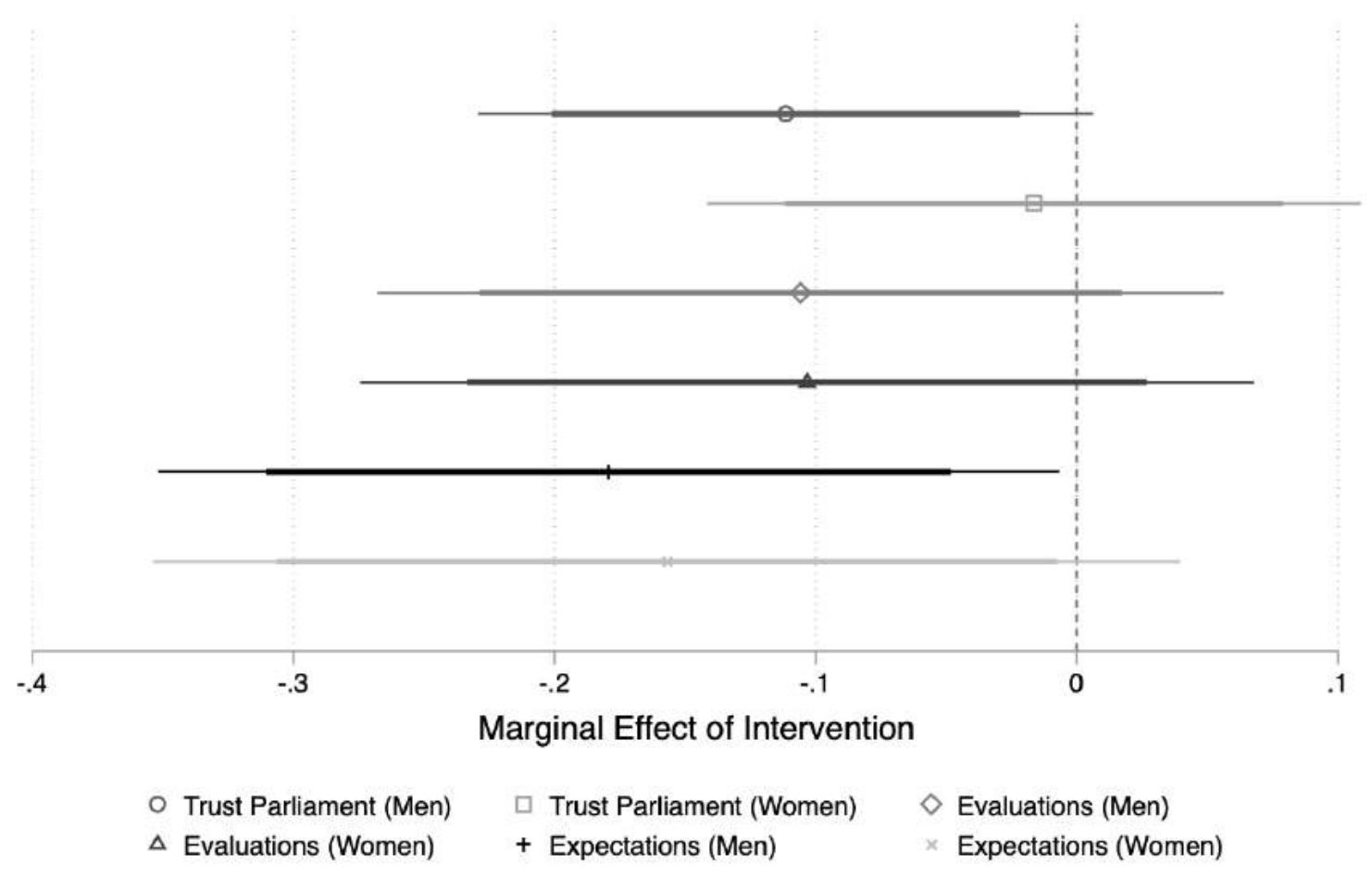

Confidence intervals at $99 \%$ and $95 \%$

Figure A5: Key results separated by gender

challenge to our main conclusion. 


\section{Full result tables}

Table A5 presents the full results on trust in Parliament, government and the EU for the effects of the 'treatment' (intervention), and the effect on trust in Parliament with region fixed effects. The results show that the effect had a negative effect uniquely for Parliament, which remains with region fixed effects at a lower level of significance.

Table A6 presents the full models (with marginal effects) for both trust and economic perceptions. 
Table A5: Results of the intervention on trust in Parliament, Government and the EU

$\begin{array}{llll}(1) & (2) & (3) & (4)\end{array}$

Parliament Government European Union With Region FE

\begin{tabular}{|c|c|c|c|c|}
\hline Treated & $\begin{array}{l}-0.0676^{*} \\
(0.0341)\end{array}$ & $\begin{array}{l}0.00412 \\
(0.0317)\end{array}$ & $\begin{array}{l}-0.0201 \\
(0.0391)\end{array}$ & $\begin{array}{r}-0.0633^{+} \\
(0.0345)\end{array}$ \\
\hline Gender & $\begin{array}{c}-0.0925^{* *} \\
(0.0296)\end{array}$ & $\begin{array}{c}-0.0814^{* *} \\
(0.0271)\end{array}$ & $\begin{array}{c}-0.113^{* * *} \\
(0.0334)\end{array}$ & $\begin{array}{c}-0.0919^{* *} \\
(0.0297)\end{array}$ \\
\hline 15 years & $\begin{array}{l}-0.0106 \\
(0.0725)\end{array}$ & $\begin{array}{c}0.0308 \\
(0.0695)\end{array}$ & $\begin{array}{l}-0.0801 \\
(0.0899)\end{array}$ & $\begin{array}{l}-0.0168 \\
(0.0732)\end{array}$ \\
\hline 16 years & $\begin{array}{c}0.0768 \\
(0.0647)\end{array}$ & $\begin{array}{c}0.0559 \\
(0.0598)\end{array}$ & $\begin{array}{c}0.0435 \\
(0.0735)\end{array}$ & $\begin{array}{c}0.0695 \\
(0.0650)\end{array}$ \\
\hline 17 years & $\begin{array}{l}0.00558 \\
(0.0649)\end{array}$ & $\begin{array}{l}-0.0267 \\
(0.0593)\end{array}$ & $\begin{array}{c}0.0269 \\
(0.0763)\end{array}$ & $\begin{array}{l}0.00198 \\
(0.0659)\end{array}$ \\
\hline 18 years & $\begin{array}{c}0.0248 \\
(0.0581)\end{array}$ & $\begin{array}{c}0.0447 \\
(0.0560)\end{array}$ & $\begin{array}{c}0.0248 \\
(0.0682)\end{array}$ & $\begin{array}{c}0.0180 \\
(0.0591)\end{array}$ \\
\hline 19 years & $\begin{array}{l}-0.00933 \\
(0.0780)\end{array}$ & $\begin{array}{l}-0.0746 \\
(0.0616)\end{array}$ & $\begin{array}{c}0.0133 \\
(0.0912)\end{array}$ & $\begin{array}{l}-0.0129 \\
(0.0779)\end{array}$ \\
\hline 20 years & $\begin{array}{c}0.0753 \\
(0.0935)\end{array}$ & $\begin{array}{c}0.121 \\
(0.0930)\end{array}$ & $\begin{array}{l}0.0404 \\
(0.101)\end{array}$ & $\begin{array}{c}0.0674 \\
(0.0940)\end{array}$ \\
\hline 21 years & $\begin{array}{l}0.0344 \\
(0.126)\end{array}$ & $\begin{array}{c}0.112 \\
(0.118)\end{array}$ & $\begin{array}{l}0.0916 \\
(0.128)\end{array}$ & $\begin{array}{l}0.0354 \\
(0.126)\end{array}$ \\
\hline $22+$ years & $\begin{array}{c}0.0493 \\
(0.0713)\end{array}$ & $\begin{array}{c}0.0171 \\
(0.0660)\end{array}$ & $\begin{array}{c}0.123 \\
(0.0794)\end{array}$ & $\begin{array}{c}0.0385 \\
(0.0713)\end{array}$ \\
\hline Still studying & $\begin{array}{c}0.0140 \\
(0.0972)\end{array}$ & $\begin{array}{c}0.0300 \\
(0.0842)\end{array}$ & $\begin{array}{l}0.0729 \\
(0.106)\end{array}$ & $\begin{array}{c}0.0117 \\
(0.0981)\end{array}$ \\
\hline No full-time education & $\begin{array}{l}-0.0366 \\
(0.0728)\end{array}$ & $\begin{array}{l}-0.0286 \\
(0.0685)\end{array}$ & $\begin{array}{l}-0.153^{+} \\
(0.0860)\end{array}$ & $\begin{array}{l}-0.0274 \\
(0.0738)\end{array}$ \\
\hline Age & $\begin{array}{l}-0.00102 \\
(0.00146)\end{array}$ & $\begin{array}{l}0.000769 \\
(0.00132)\end{array}$ & $\begin{array}{l}-0.00233 \\
(0.00167)\end{array}$ & $\begin{array}{l}-0.00106 \\
(0.00147)\end{array}$ \\
\hline Managers & $\begin{array}{l}-0.00679 \\
(0.0898)\end{array}$ & $\begin{array}{l}-0.0258 \\
(0.0795)\end{array}$ & $\begin{array}{c}0.0517 \\
(0.0951)\end{array}$ & $\begin{array}{r}-0.00366 \\
(0.0895)\end{array}$ \\
\hline Other white collar & $\begin{array}{l}-0.0435 \\
(0.0743)\end{array}$ & $\begin{array}{c}0.0230 \\
(0.0680)\end{array}$ & $\begin{array}{l}-0.0415 \\
(0.0855)\end{array}$ & $\begin{array}{l}-0.0389 \\
(0.0745)\end{array}$ \\
\hline Manual workers & $\begin{array}{c}-0.0182 \\
(0.0659)\end{array}$ & $\begin{array}{c}0.0213 \\
(0.0588)\end{array}$ & $\begin{array}{l}-0.0699 \\
(0.0733)\end{array}$ & $\begin{array}{r}-0.00933 \\
(0.0666)\end{array}$ \\
\hline House persons & $\begin{array}{c}0.0573 \\
(0.0901)\end{array}$ & $\begin{array}{l}-0.0209 \\
(0.0752)\end{array}$ & $\begin{array}{c}-0.119 \\
(0.0985)\end{array}$ & $\begin{array}{c}0.0675 \\
(0.0908)\end{array}$ \\
\hline Unemployed & $\begin{array}{l}-0.0278 \\
(0.0695)\end{array}$ & $\begin{array}{c}-0.000967 \\
(0.0618)\end{array}$ & $\begin{array}{l}-0.0619 \\
(0.0774)\end{array}$ & $\begin{array}{l}-0.0158 \\
(0.0701)\end{array}$ \\
\hline Retired & $\begin{array}{c}0.0267 \\
(0.0720)\end{array}$ & $\begin{array}{c}0.0302 \\
(0.0662)\end{array}$ & $\begin{array}{l}0.00314 \\
(0.0804)\end{array}$ & $\begin{array}{c}0.0341 \\
(0.0726)\end{array}$ \\
\hline Constant & $\begin{array}{c}0.468^{* * *} \\
(0.111)\end{array}$ & $\begin{array}{l}0.268^{* *} \\
(0.100)\end{array}$ & $\begin{array}{c}0.786^{* * *} \\
(0.122)\end{array}$ & $\begin{array}{c}0.460^{* * *} \\
(0.112)\end{array}$ \\
\hline Region Fixed Effect & & & & $\checkmark$ \\
\hline $\begin{array}{l}\text { Observations } \\
\text { bic }\end{array}$ & $\begin{array}{c}980 \\
1311.5\end{array}$ & $\begin{array}{c}986 \\
1126.9\end{array}$ & $\begin{array}{c}924 \\
1430.1\end{array}$ & $\begin{array}{c}980 \\
1336.3\end{array}$ \\
\hline
\end{tabular}

Standard errors in parentheses

${ }^{+} p<0.10,{ }^{*} p<0.05,{ }^{* *} p<0.01,{ }^{* * *} p<0.001$ 
Table A6: Main models as presented in figure 1

\begin{tabular}{|c|c|c|c|}
\hline & $\begin{array}{c}(1) \\
\text { Trust in Parliament }\end{array}$ & $\begin{array}{c}(2) \\
\text { Evaluations }\end{array}$ & $\begin{array}{c}(3) \\
\text { Expectations }\end{array}$ \\
\hline Treated & $\begin{array}{l}-0.0676^{*} \\
(0.0341)\end{array}$ & $\begin{array}{l}-0.106^{*} \\
(0.0435)\end{array}$ & $\begin{array}{l}-0.171^{* * *} \\
(0.0477)\end{array}$ \\
\hline Gender & $\begin{array}{c}-0.0925^{* *} \\
(0.0296)\end{array}$ & $\begin{array}{l}-0.0448 \\
(0.0372)\end{array}$ & $\begin{array}{l}-0.00284 \\
(0.0423)\end{array}$ \\
\hline 15 years & $\begin{array}{l}-0.0106 \\
(0.0725)\end{array}$ & $\begin{array}{c}0.0894 \\
(0.0818)\end{array}$ & $\begin{array}{r}-0.0119 \\
(0.110)\end{array}$ \\
\hline 16 years & $\begin{array}{c}0.0768 \\
(0.0647)\end{array}$ & $\begin{array}{l}0.00202 \\
(0.0809)\end{array}$ & $\begin{array}{l}0.0329 \\
(0.103)\end{array}$ \\
\hline 17 years & $\begin{array}{l}0.00558 \\
(0.0649)\end{array}$ & $\begin{array}{c}0.160^{+} \\
(0.0901)\end{array}$ & $\begin{array}{c}0.0107 \\
(0.0986)\end{array}$ \\
\hline 18 years & $\begin{array}{c}0.0248 \\
(0.0581)\end{array}$ & $\begin{array}{c}0.108 \\
(0.0906)\end{array}$ & $\begin{array}{r}-0.00407 \\
(0.0861)\end{array}$ \\
\hline 19 years & $\begin{array}{r}-0.00933 \\
(0.0780)\end{array}$ & $\begin{array}{c}-0.0215 \\
(0.100)\end{array}$ & $\begin{array}{l}-0.135 \\
(0.110)\end{array}$ \\
\hline 20 years & $\begin{array}{c}0.0753 \\
(0.0935)\end{array}$ & $\begin{array}{l}0.0627 \\
(0.114)\end{array}$ & $\begin{array}{l}0.0567 \\
(0.145)\end{array}$ \\
\hline 21 years & $\begin{array}{l}0.0344 \\
(0.126)\end{array}$ & $\begin{array}{r}-0.0525 \\
(0.125)\end{array}$ & $\begin{array}{c}0.220 \\
(0.171)\end{array}$ \\
\hline $22+$ years & $\begin{array}{c}0.0493 \\
(0.0713)\end{array}$ & $\begin{array}{l}-0.120 \\
(0.103)\end{array}$ & $\begin{array}{l}-0.198^{*} \\
(0.0883)\end{array}$ \\
\hline Still studying & $\begin{array}{c}0.0140 \\
(0.0972)\end{array}$ & $\begin{array}{l}0.0321 \\
(0.125)\end{array}$ & $\begin{array}{c}-0.00949 \\
(0.148)\end{array}$ \\
\hline No full-time education & $\begin{array}{l}-0.0366 \\
(0.0728)\end{array}$ & $\begin{array}{c}-0.107 \\
(0.0929)\end{array}$ & $\begin{array}{l}-0.177^{*} \\
(0.0813)\end{array}$ \\
\hline Age & $\begin{array}{l}-0.00102 \\
(0.00146)\end{array}$ & $\begin{array}{l}0.000492 \\
(0.00177)\end{array}$ & $\begin{array}{r}-0.00415^{+} \\
(0.00225)\end{array}$ \\
\hline Managers & $\begin{array}{l}-0.00679 \\
(0.0898)\end{array}$ & $\begin{array}{l}0.0849 \\
(0.133)\end{array}$ & $\begin{array}{c}0.120 \\
(0.126)\end{array}$ \\
\hline Other white collar & $\begin{array}{l}-0.0435 \\
(0.0743)\end{array}$ & $\begin{array}{r}-0.0157 \\
(0.107)\end{array}$ & $\begin{array}{r}-0.0856 \\
(0.104)\end{array}$ \\
\hline Manual workers & $\begin{array}{l}-0.0182 \\
(0.0659)\end{array}$ & $\begin{array}{l}-0.0728 \\
(0.0883)\end{array}$ & $\begin{array}{l}-0.0255 \\
(0.0882)\end{array}$ \\
\hline House persons & $\begin{array}{c}0.0573 \\
(0.0901)\end{array}$ & $\begin{array}{l}-0.131 \\
(0.110)\end{array}$ & $\begin{array}{l}0.0415 \\
(0.123)\end{array}$ \\
\hline Unemployed & $\begin{array}{l}-0.0278 \\
(0.0695)\end{array}$ & $\begin{array}{c}-0.113 \\
(0.0913)\end{array}$ & $\begin{array}{l}-0.0946 \\
(0.0929)\end{array}$ \\
\hline Retired & $\begin{array}{c}0.0267 \\
(0.0720)\end{array}$ & $\begin{array}{l}-0.0406 \\
(0.0917)\end{array}$ & $\begin{array}{l}-0.0509 \\
(0.0933)\end{array}$ \\
\hline Constant & $\begin{array}{c}0.468^{* * *} \\
(0.111)\end{array}$ & $\begin{array}{c}1.631^{* * *} \\
(0.141)\end{array}$ & $\begin{array}{c}1.698^{* * *} \\
(0.166)\end{array}$ \\
\hline Observations & 980 & 1022 & 967 \\
\hline
\end{tabular}




\section{Placebo tests}

Table A7 displays the results for a number of placebo tests on political trust. First, placebos 1 and 2 show the coefficients when the 'treatment' day is set to the median date of fieldwork, both including (first column) and excluding (second column) the actual treated group. The next two columns show an arbitrary choice of 6th and 5th days of fieldwork. The final column reduces the bandwidth to 3 days either side of the actual treatment day; in other words, we reduce the sample to observations only separated by a few days, ruling out as much as possible (whilst retaining power) spurious time trends or sampling effects. Collectively, these results show no effects for the placebo treatments and a significant, large effect for the reduced bandwidth.

Table A7: Placebo Tests for Political Trust (Average Marginal Effects Reported)

\begin{tabular}{|c|c|c|c|c|c|}
\hline & $\begin{array}{c}(1) \\
\text { Median (with Treated) }\end{array}$ & $\begin{array}{c}(2) \\
\text { Median (without treated) }\end{array}$ & $\begin{array}{c}(3) \\
\text { 6th Day }\end{array}$ & $\begin{array}{c}(4) \\
5 \text { th day }\end{array}$ & $\begin{array}{c}(5) \\
\text { Reduced bandwidth }\end{array}$ \\
\hline Placebo 1 & $\begin{array}{c}-0.000730 \\
(0.0323)\end{array}$ & & & & \\
\hline Placebo 2 & & $\begin{array}{c}0.0127 \\
(0.0345)\end{array}$ & & & \\
\hline Placebo 3 & & & $\begin{array}{c}0.0247 \\
(0.0371)\end{array}$ & & \\
\hline Placebo 4 & & & & $\begin{array}{c}0.0466 \\
(0.0471)\end{array}$ & \\
\hline Treated & & & & & $\begin{array}{c}-0.113^{*} \\
(0.0472)\end{array}$ \\
\hline Constant & $\begin{array}{c}0.412^{* * *} \\
(0.112)\end{array}$ & $\begin{array}{c}0.516^{\text {*** }} \\
(0.133)\end{array}$ & $\begin{array}{c}0.504^{* * *} \\
(0.135)\end{array}$ & $\begin{array}{c}0.476^{\text {*** }} \\
(0.141)\end{array}$ & $\begin{array}{c}0.402^{*} \\
(0.158)\end{array}$ \\
\hline Socio-demographics & $\checkmark$ & $\checkmark$ & $\checkmark$ & $\checkmark$ & $\checkmark$ \\
\hline Region Fixed Effect & $\checkmark$ & $\checkmark$ & $\checkmark$ & $\checkmark$ & $\checkmark$ \\
\hline Observations & 980 & 745 & 745 & 745 & 463 \\
\hline
\end{tabular}

Figure A6 presents the same tests but for all economic perceptions. The results are consistent; in fact, the placebos have a positive coefficient, which makes the negative coefficient of our treatment day even more surprising.

We also perform a permutation test, which reproduces the analysis by randomly assigning the 'treatment' date to any of the dates in the survey. These are presented in figure A7. As can be seen, the actual coefficient (red dashed line) is extremely unlikely to be random, 


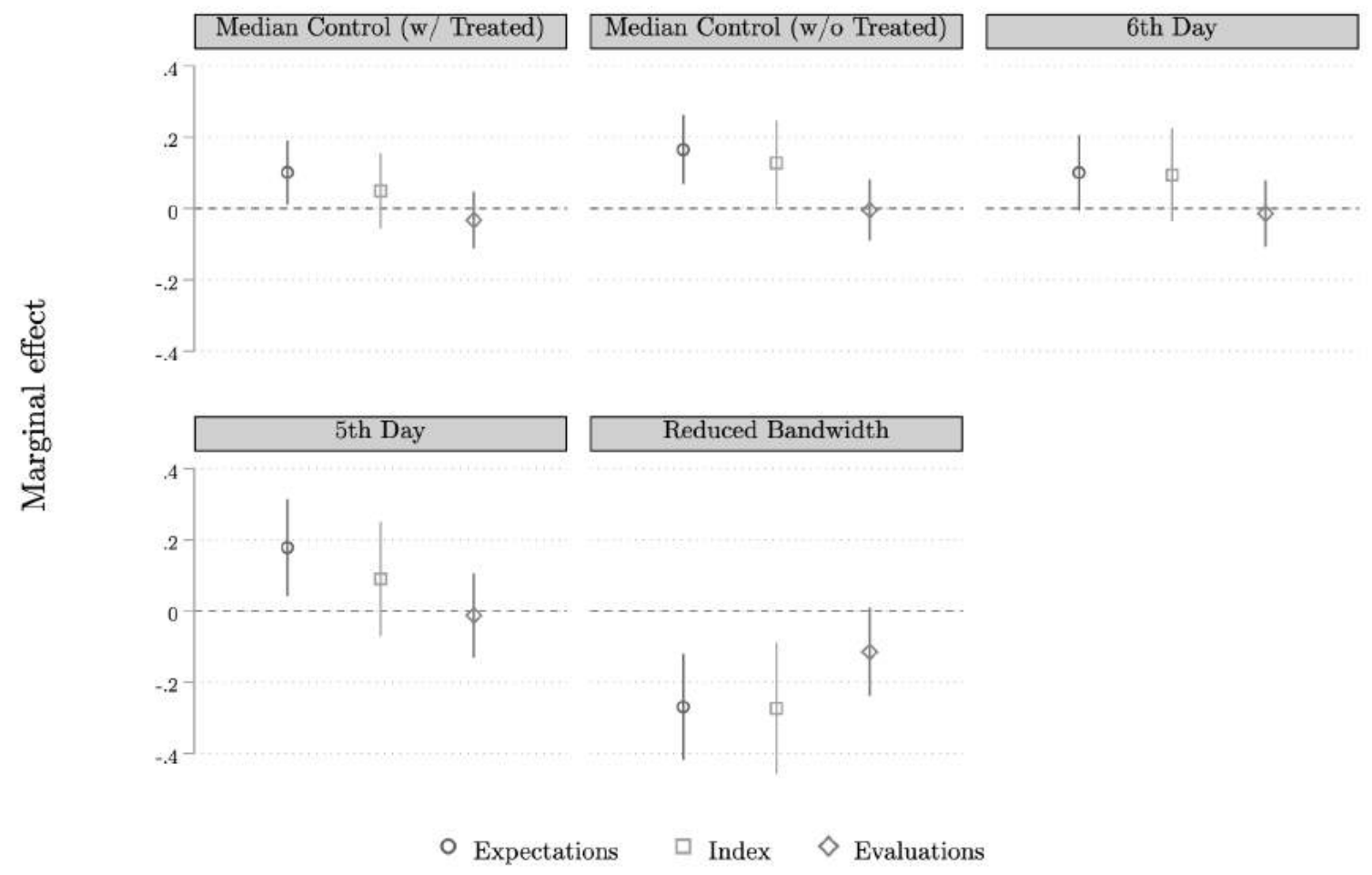

Figure A6: Coefficient plot of placebo tests on economic perceptions

and the majority of randomly selected dates peak over zero.

As a final test, we change our unit of analysis rather than object. In figure A8 we show the effect of the treatment date in all countries (running an identical model in all countries individually). This shows that, except in Malta, the significant negative effect is only in Portugal, though other countries have non-significant negative effects. We note that in Malta, a strike was announced around our treatment day. It is possible that this is driving the effect as we have no reason to suspect a spillover effect. These null effects also reassure us that there is no event happening in another country (e.g Spain) that is also effecting our sample in Portugal. 


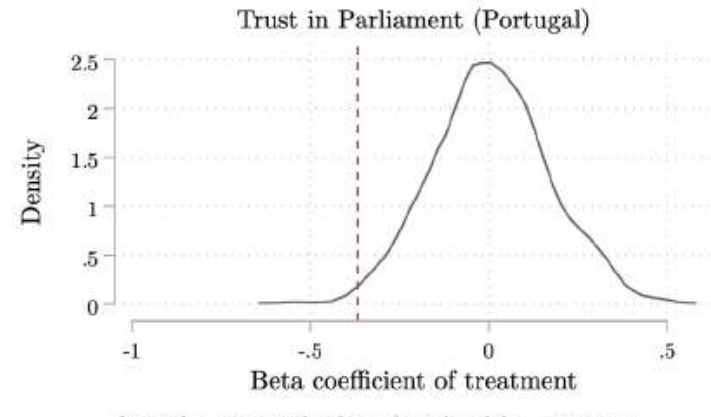

kernel $=$ epanechnikov, bandwidth $=0.0352$

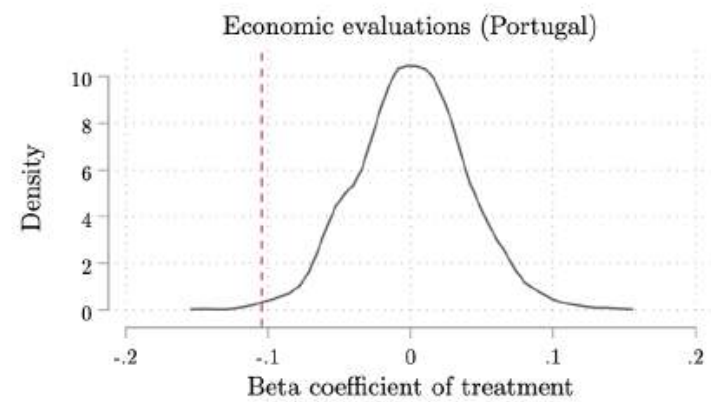

kernel $=$ epanechnikov, bandwidth $=0.0082$

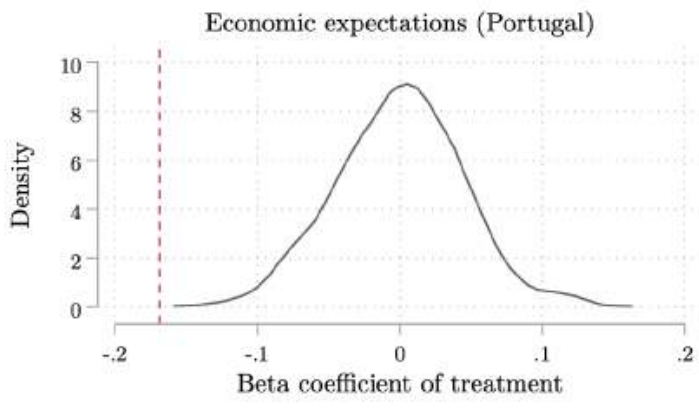

kernel $=$ epanechnikov, bandwidth $=0.0100$

Figure A7: Permutation test (1,000 iterations) on trust in Parliament and economic perceptions 


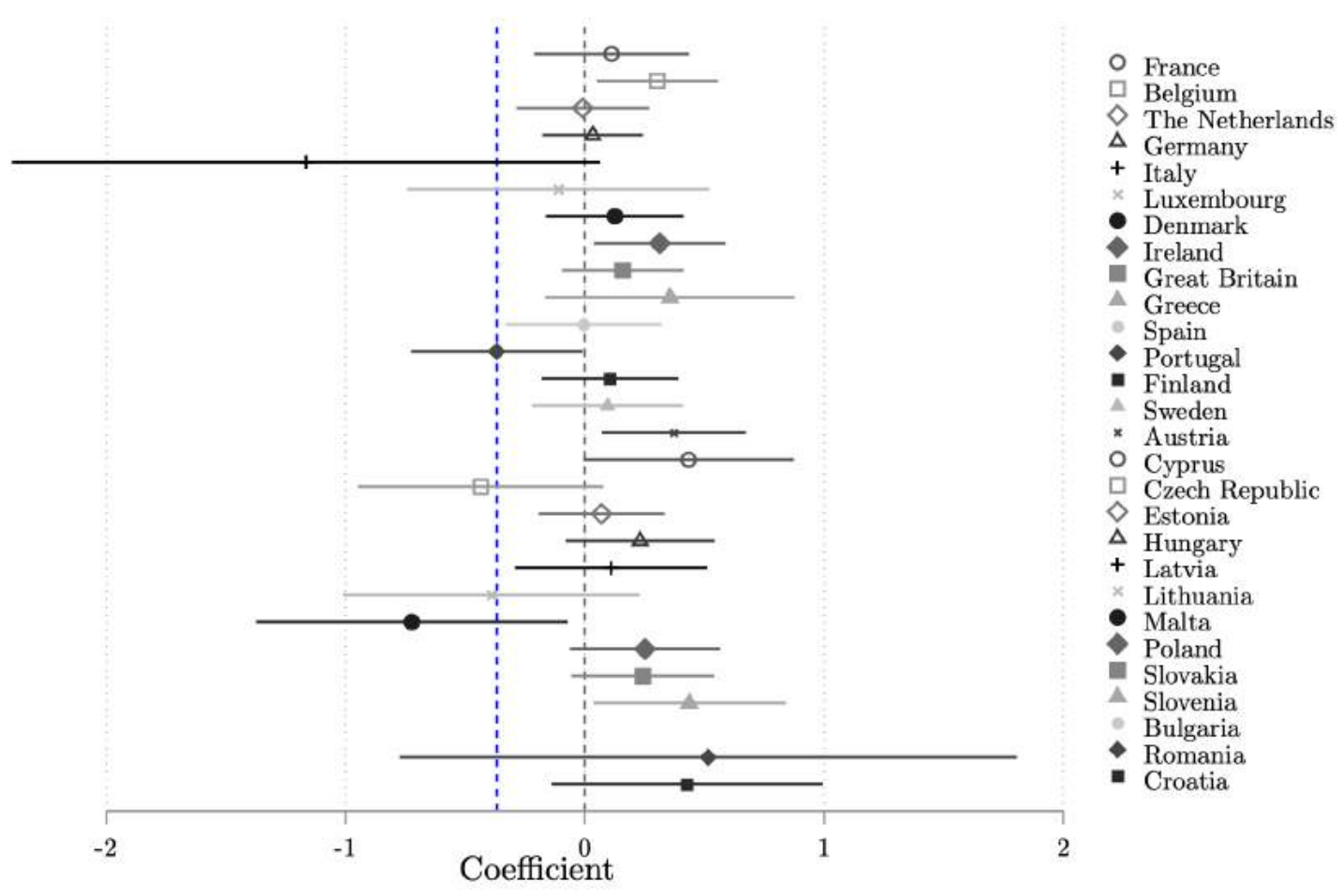

Portugese coefficient in blue dashed line. Zero in grey dashed line.

Figure A8: Treatment on multiple units (all EU countries) 


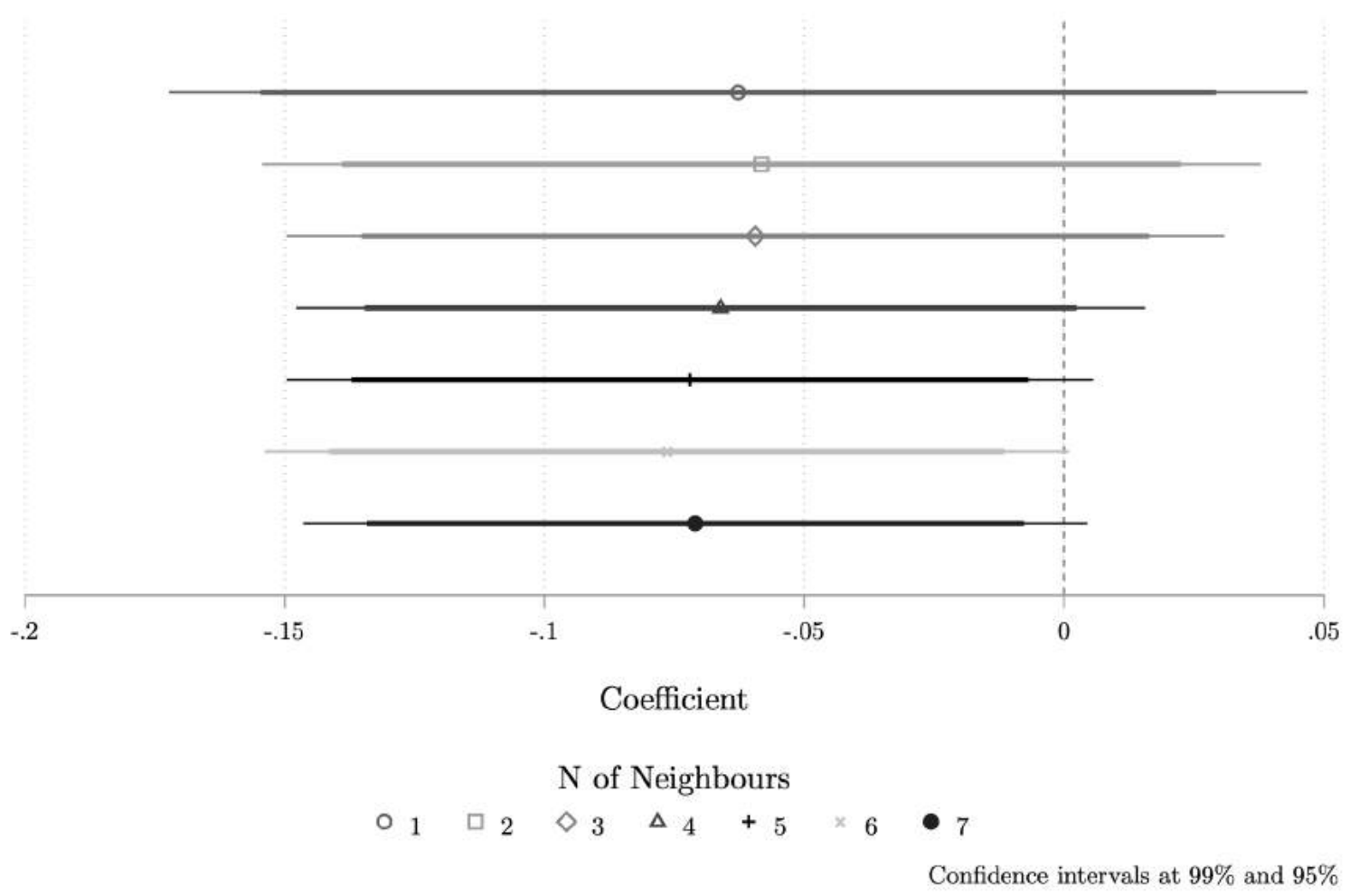

Figure A9: Coefficient with near-neighbour matching with increasing $\mathrm{N}$ of neighbours (Political trust)

\section{Matching robustness tests}

Figures A9, A10 and A11 present results from near-neighbour matching (NNM), showing the average treatment effect. NNM matches similar individuals from the treatment and control groups, which we have matched on our covariates (perfect matching on gender). We also 'oversample' the neighbours, such that increasing neighbours uses more information to construct the counterfactual. These show that the point estimate does not change, at all in the case of political trust. However, we do see the significance reduce with fewer neighbours. We don't see this as an issue. The trade-off of increasing the number of neighbours is precisely variance versus bias. As such, the fact that our estimates do not change suggest that we do not inherit much bias (at least not vis-á-vis the presented model) but reduce our uncertainty. 


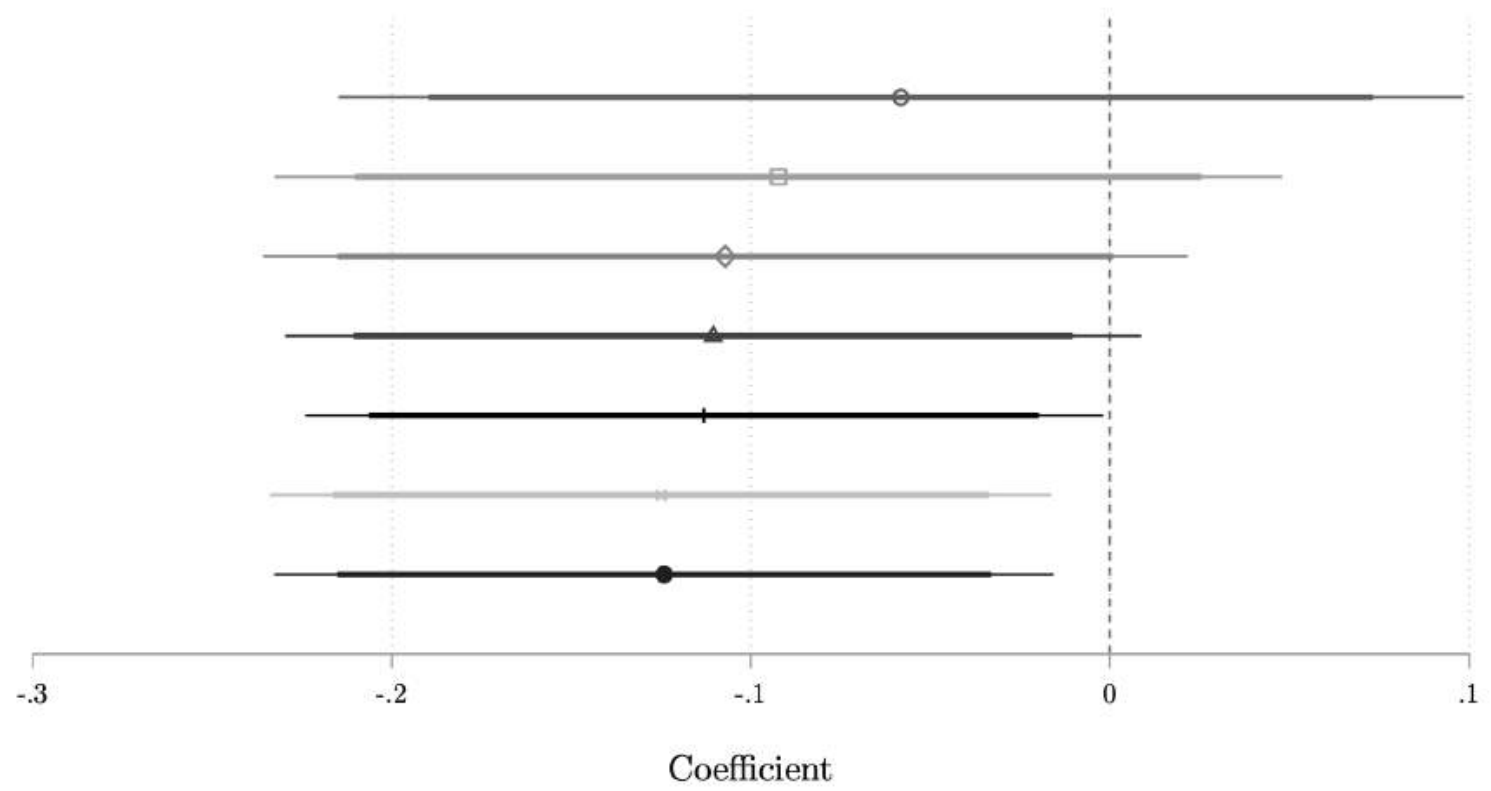

$\mathrm{N}$ of Neighbours

$\circ_{1} \square_{2} \diamond_{3} \Delta_{4}+5 \quad{ }_{6}$

Confidence intervals at $99 \%$ and $95 \%$

Figure A10: Coefficient with near-neighbour matching with increasing $\mathrm{N}$ of neighbours (Economic expectations) 


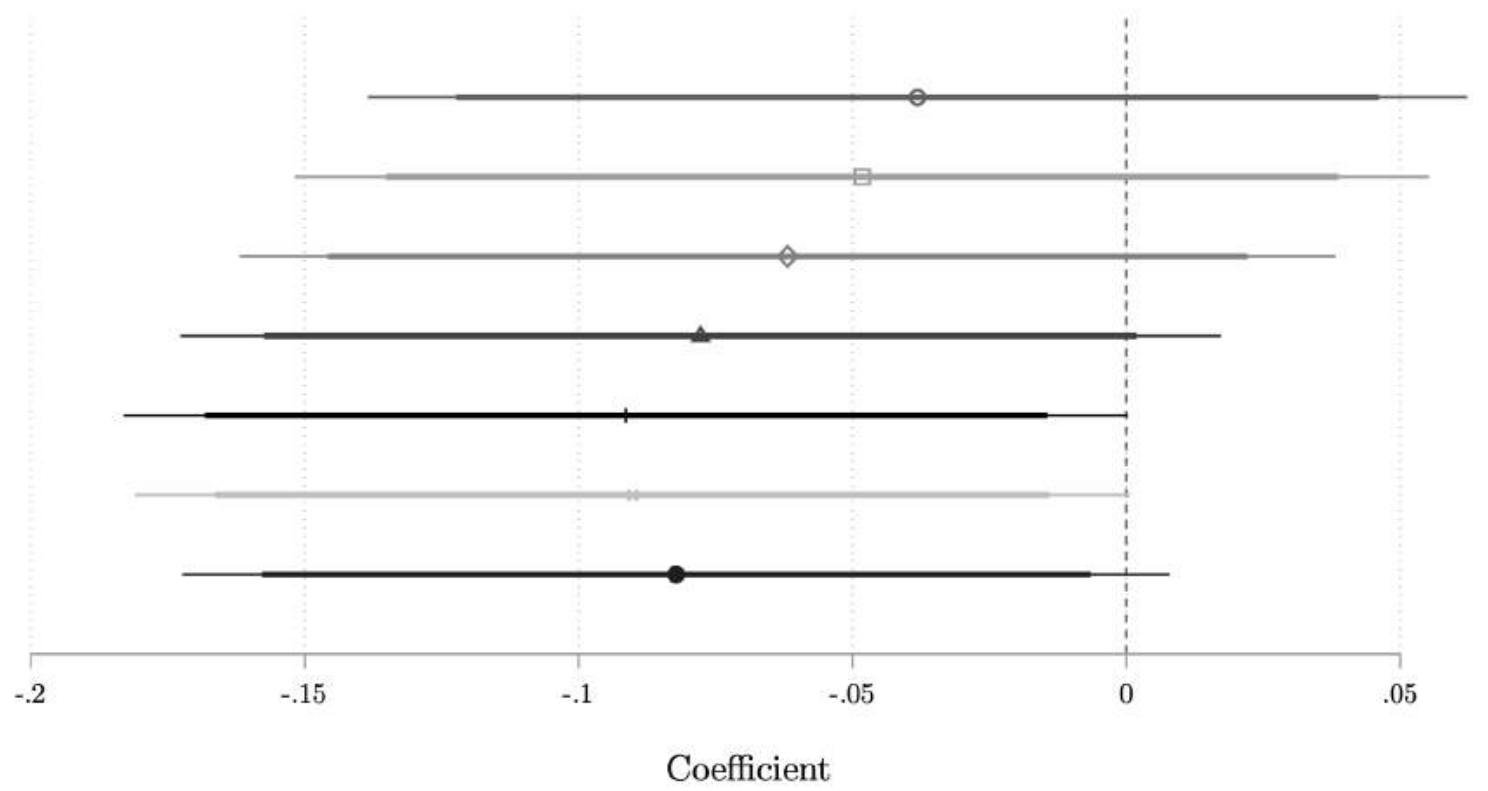

$\mathrm{N}$ of Neighbours

$\circ_{1} \square_{2} \diamond_{3} \Delta_{4}+5 \quad{ }_{6}$

Confidence intervals at $99 \%$ and $95 \%$

Figure A11: Coefficient with near-neighbour matching with increasing $\mathrm{N}$ of neighbours (Economic evaluations) 


\section{Mediation Analysis}

Table A8 lists the iterations of the Eurobarometer surveys that were included in the aggregate-level mediation analysis. Those waves listed below represent the waves between 2005 and 20115 that included both measures of satisfaction with democracy and economic evaluations.

Table A8: Eurobarometer survey waves included in aggregate analysis

\begin{tabular}{ll}
\hline Year & Eurobarometer survey \\
\hline 2005 & EB 63.1 \\
2006 & EB65.2 \\
2007 & EB68.1 \\
2009 & EB72.4 \\
2010 & EB73.4 \\
2011 & EB76.3 \\
2012 & EB77.3, EB78.1 \\
2013 & EB79.5, EB80.1 \\
2014 & EB81.2, EB81.4, EB82.3 \\
2015 & EB83.3, EB84.3 \\
\hline
\end{tabular}

Table A9: Descriptive statistics for mediation analysis

\begin{tabular}{lccccc}
\hline & Count & Mean & Sd & Min & Max \\
\hline SWD & 266 & 2.46 & 0.39 & 1.639859 & 3.366358 \\
Economic perceptions & 293 & 2.17 & 0.49 & 1.185662 & 3.594491 \\
Unemployment change & 293 & 0.08 & 1.75 & -4.400001 & 9.8 \\
Debt change & 293 & 2.78 & 7.35 & -31.45014 & 56.31417 \\
Deficit change & 293 & 0.00 & 2.90 & -18.31358 & 19.47701 \\
Interest rates change & 288 & -0.26 & 1.58 & -12.44333 & 8.389999 \\
Intervention & 293 & 0.07 & 0.25 & 0 & 1 \\
Year & 293 & 2010.14 & 3.14 & 2005 & 2015 \\
\hline$N$ & 293 & & & & \\
\hline
\end{tabular}


Effect of intervention

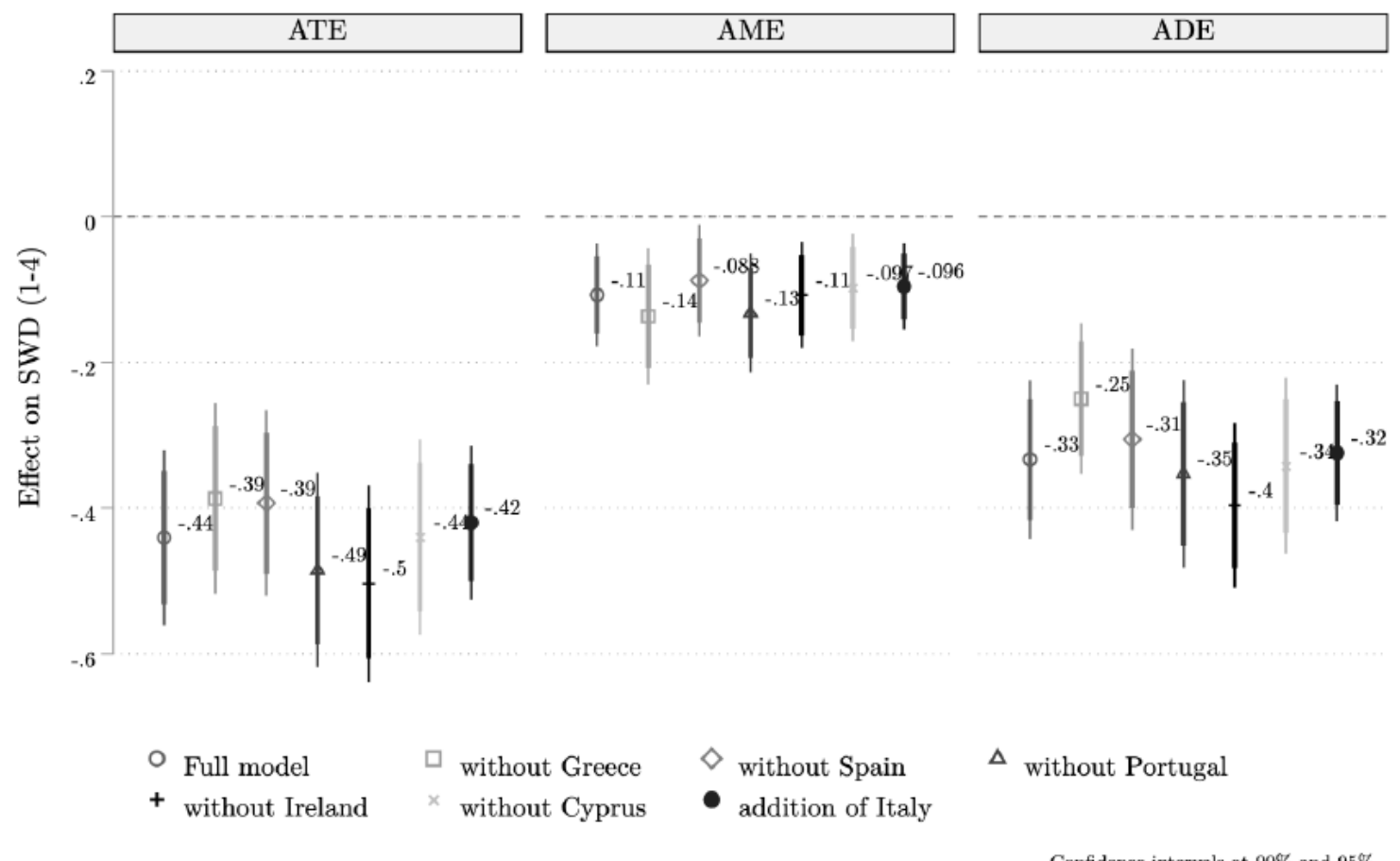

Figure A12: Influential country test

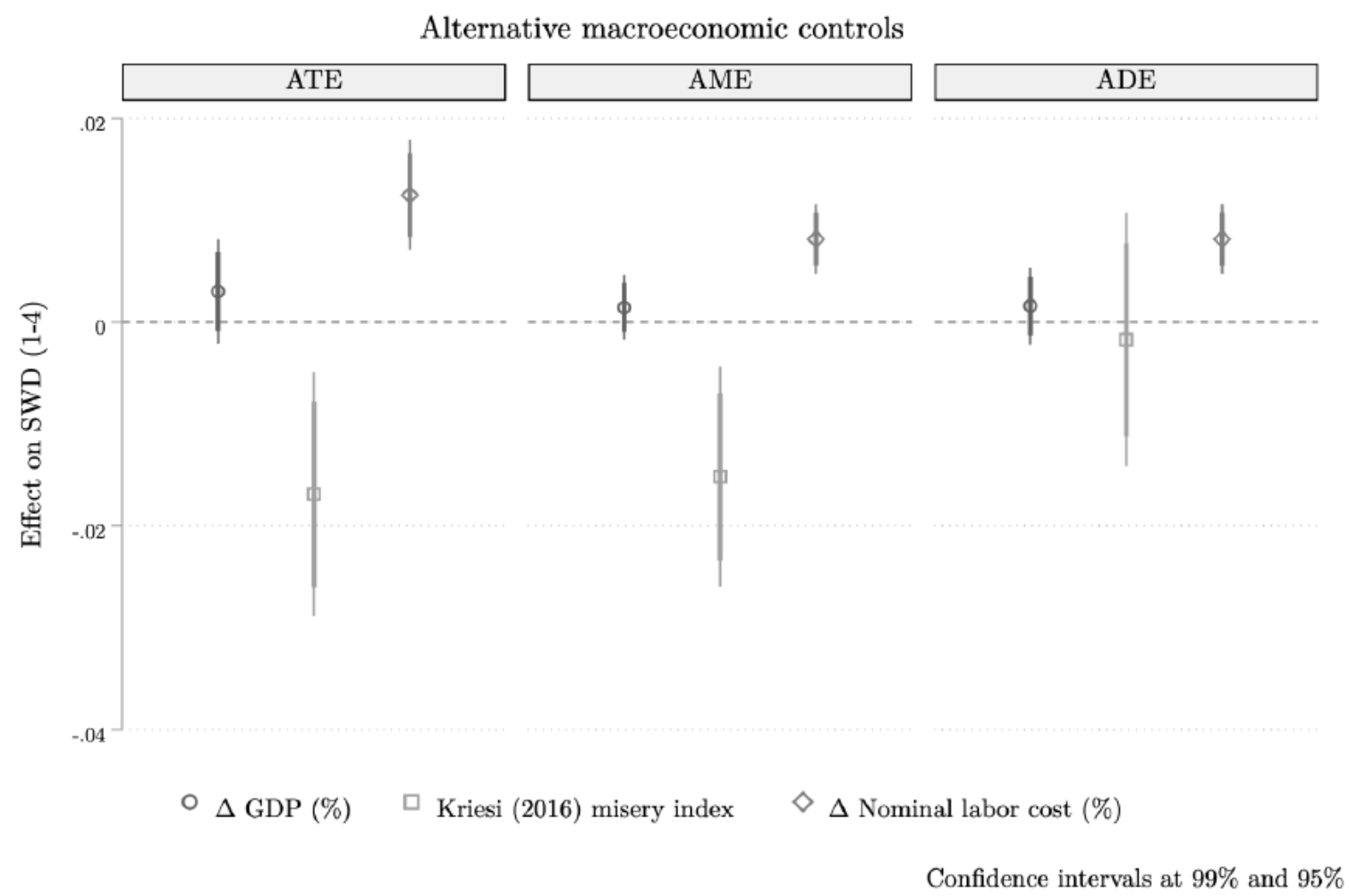

Figure A13: Additional models 
In Figure A14 we visualise the shift in the level of SWD among those countries who were intervened-in before the height of the Eurozone crisis. This includes Hungary (first bailout out in December 2008, Latvia (first bailed out in December 2008), and Romania (first bailout out in March 2009). These trends lines demonstrate that, whilst Latvia and Romania experienced a drop in SWD in Eurobarometer waves held after they were bailed out, SWD returned to normal levels very shortly afterwards. Benchmarking these changes from the pre-intervention trends observed in Greece and Spain, however demonstrates that the changes in SWD in these latter countries was of a substantively larger magnitude. This may be the result of the already very low levels of SWD in these countries exercising a floor effect. Note also that given part of our theorised mechanism is that the political information that individuals were being exposed to would likely engender an individuallevel reevaluations of the political and economic climate, it is worth noting that the popular saliency of the bailouts received in Hungary, Latvia and Romania were dwarfed by those experienced by countries during the Eurozone crisis.

We do, however, test whether our conclusions are in any way sensitive to considering the intervention of these countries. In Figure A15 we re-estimate our main mediation analysis to include Hungary, Latvia and Romania in the intervened-in "treatment" group. Doing so, whilst reducing the overall point-estimate - likely the result of these new additions being resilient to becoming even less satisfied with democracy - our conclusions hold. 
Trends in SWD among pre- and post-Eurozone crisis interevned-in countries

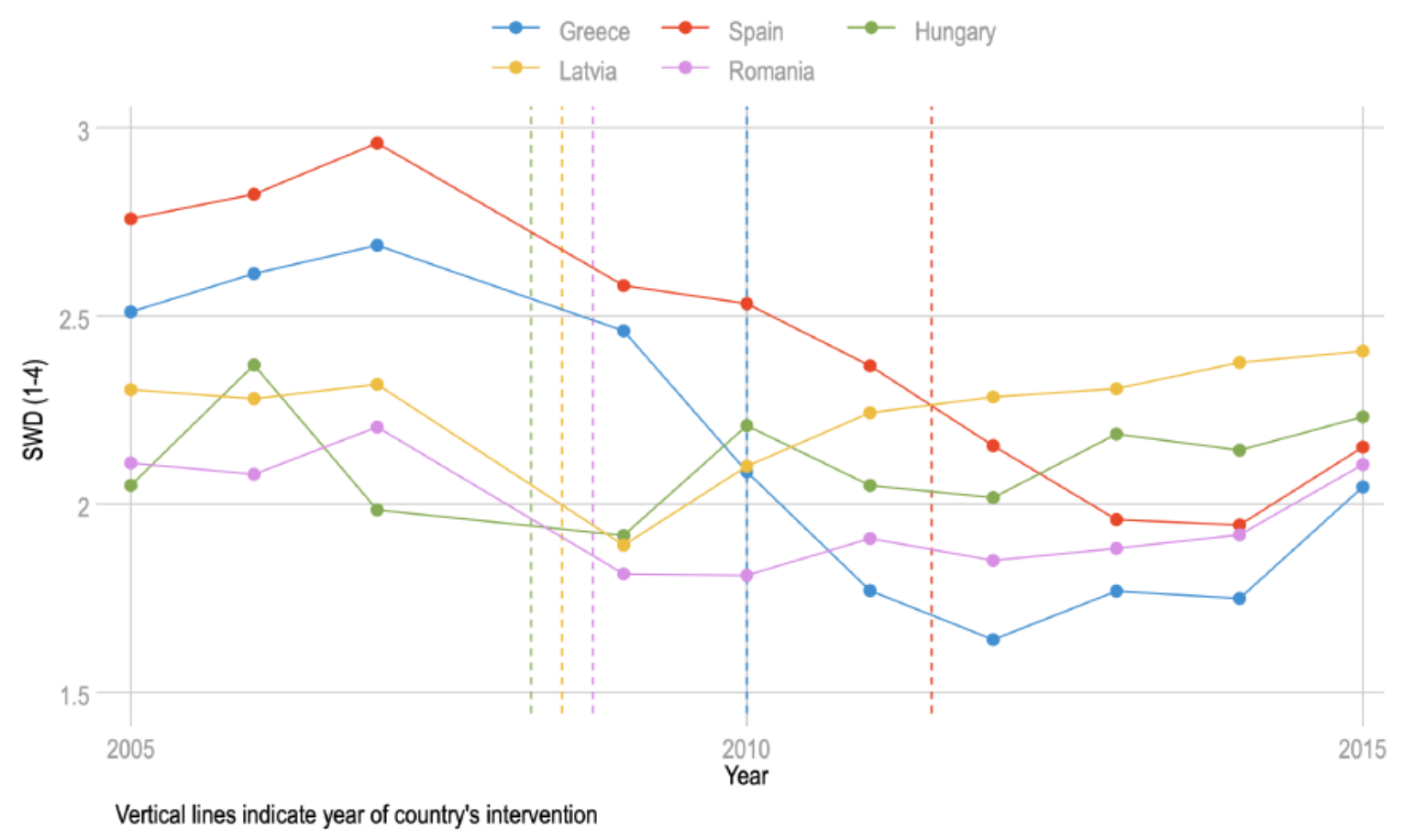

Figure A14: Trends in SWD among early intervened-in states and those intervened-in during Eurozone crisis 


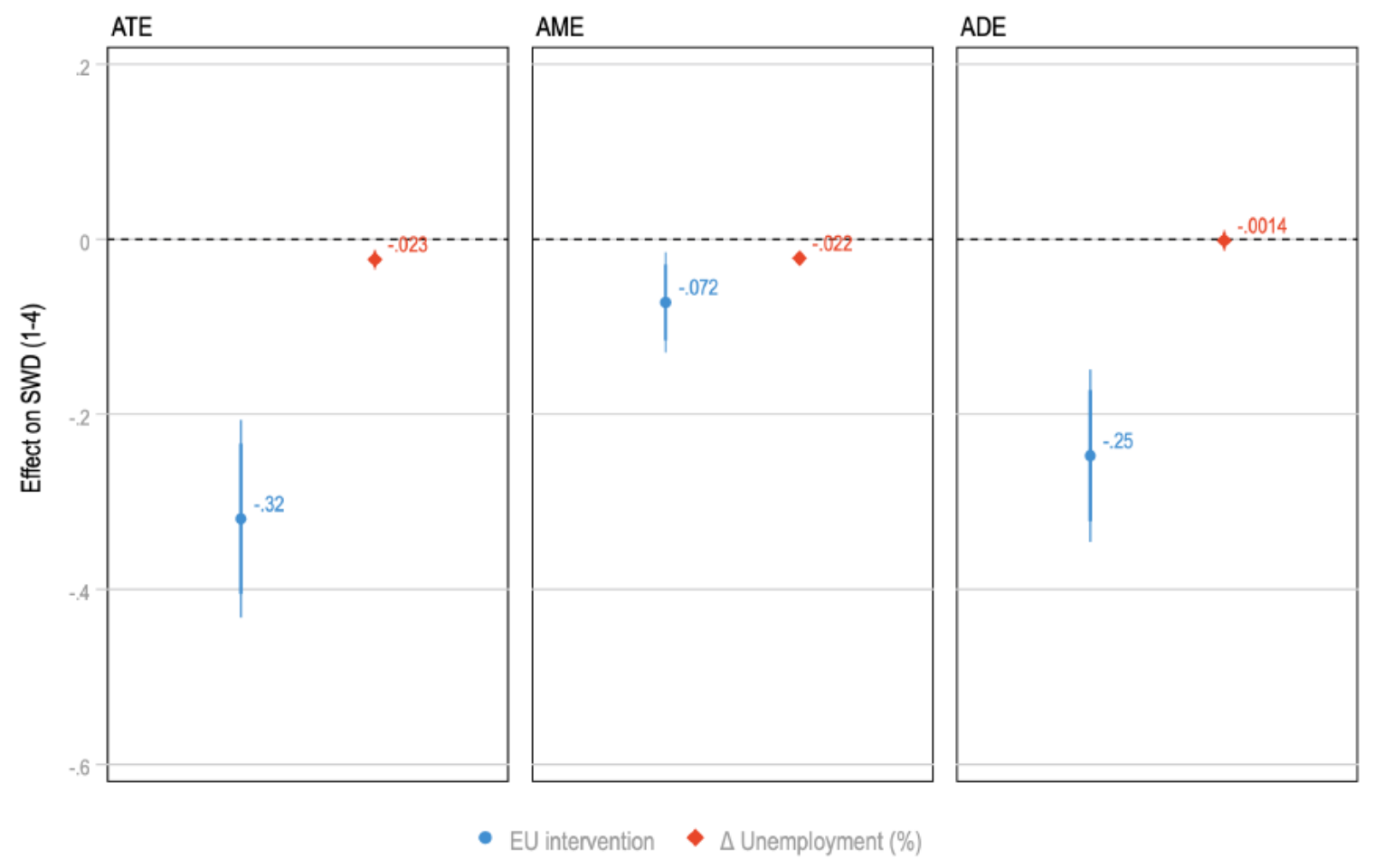

Figure A15: Replication of Figure 3 including Hungary, Latvia \& Romania in intervention group 


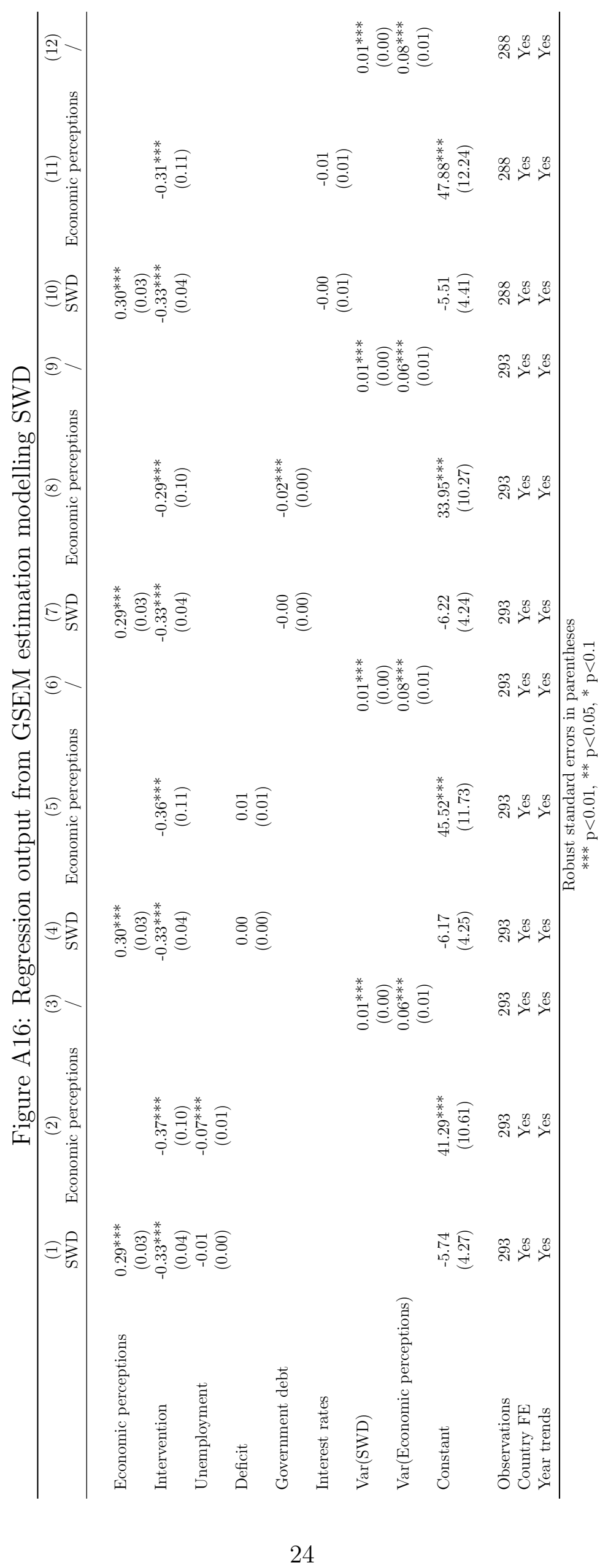




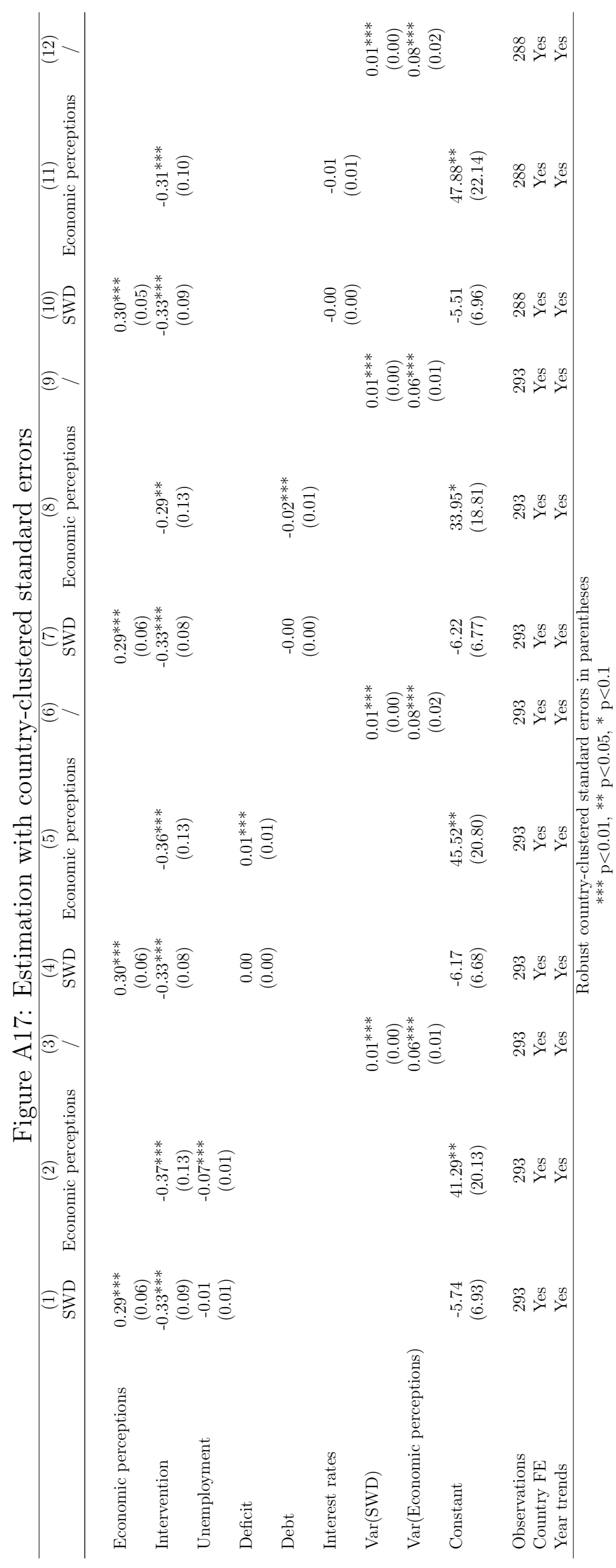




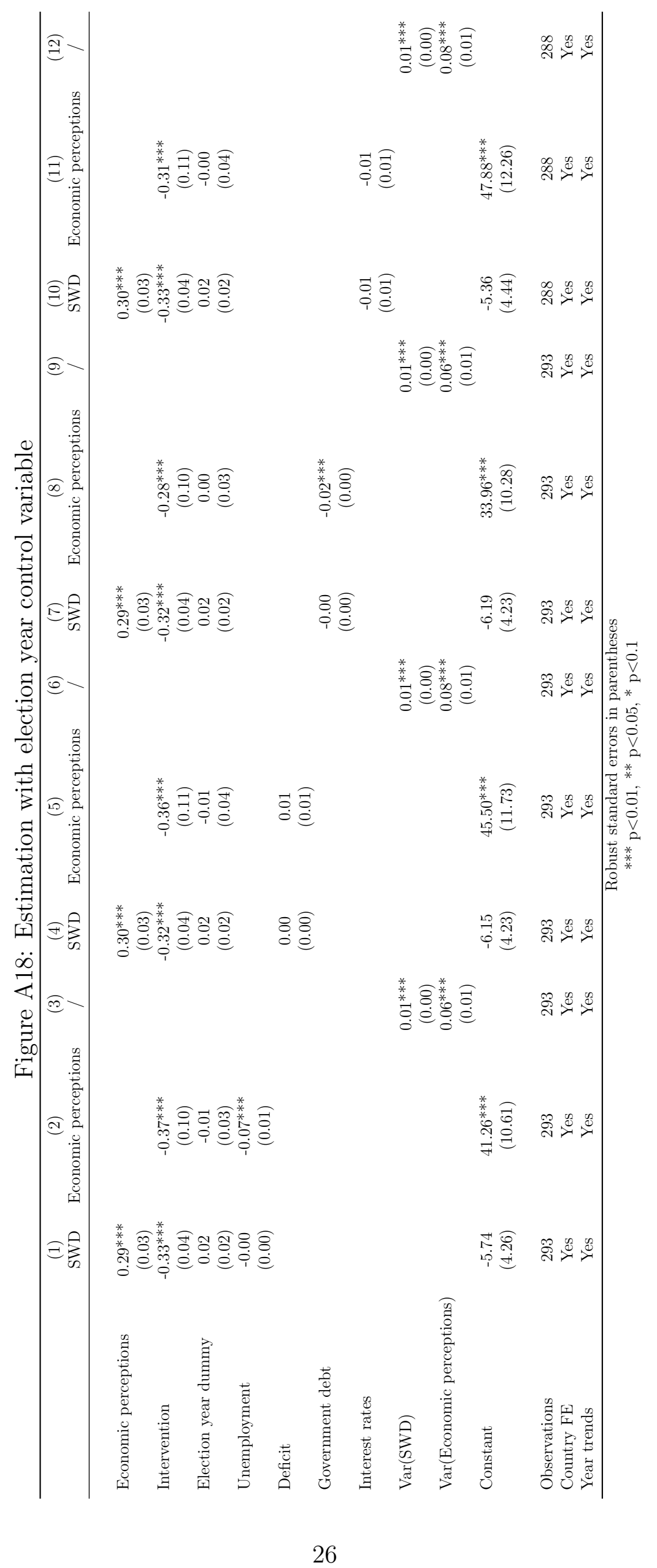




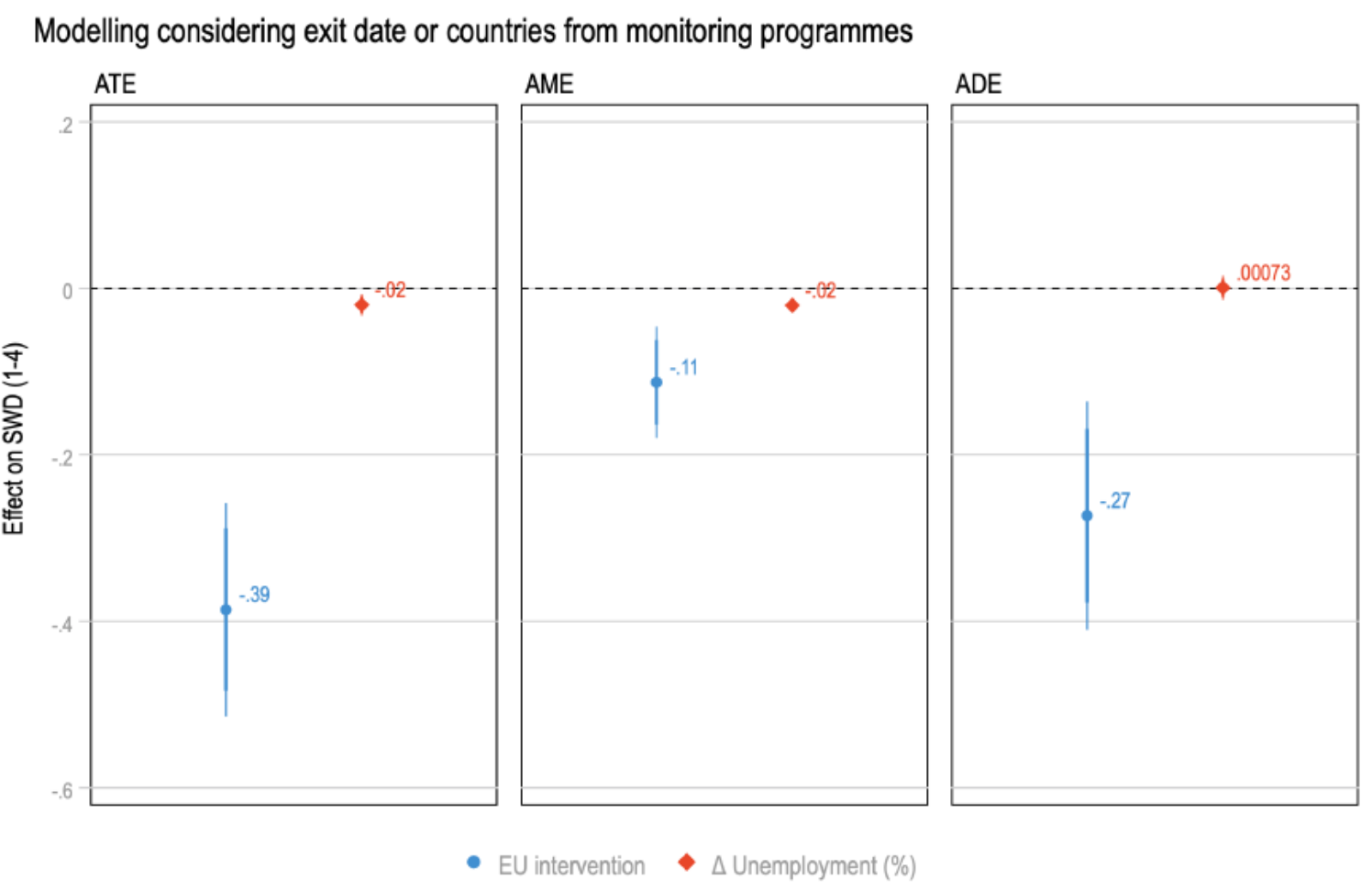

Figure A19: Models sensitive to longevity and exit of bailout programs

Mediation analysis using individual-level data (Portugal)

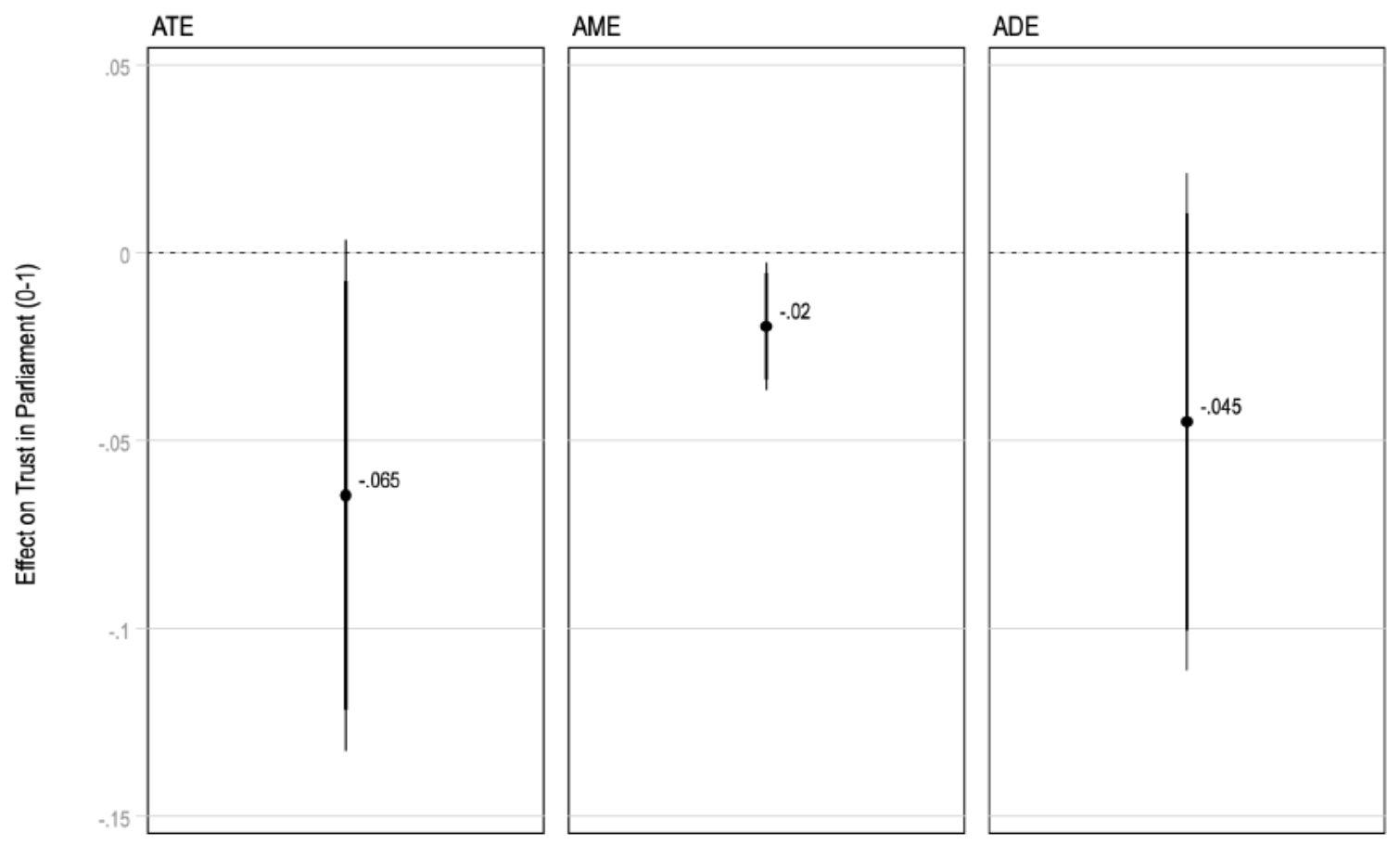

Figure A20: Effect of intervention in Portugal 